Universidad de Lima

Escuela de Posgrado

Maestría en Derecho Empresarial

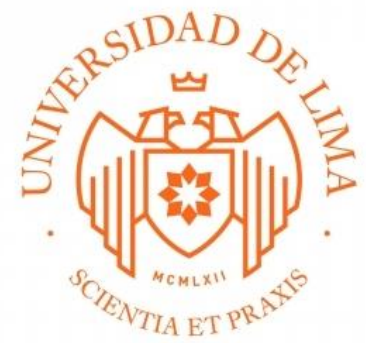

\title{
RESPONSABILIDAD CIVIL MÉDICA Y APLICACIÓN DE LEVANTAMIENTO DEL VELO SOCIETARIO
}

Trabajo de investigación para optar el Grado Académico de Maestro en Derecho Empresarial

\section{Mayra Alejandra Duffoo Quintos} 20162710

Asesor

Desirée Orsini

Lima - Perú

Enero de 2020 


\section{TABLA DE CONTENIDO}

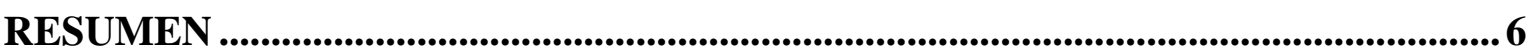

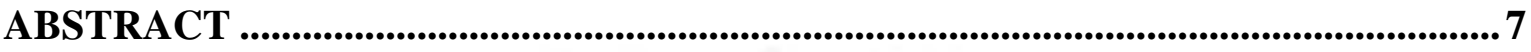

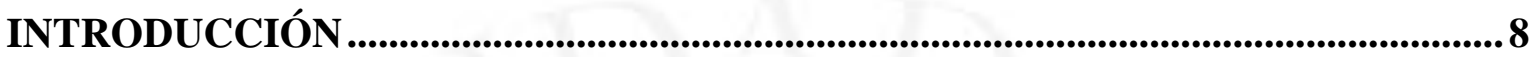

CAPITULO I: ESTABLECIMIENTOS MÉDICOS Y EL MECANISMO PARA

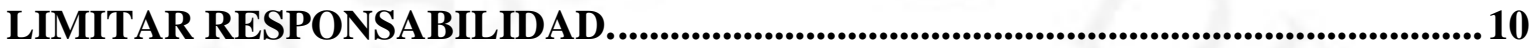

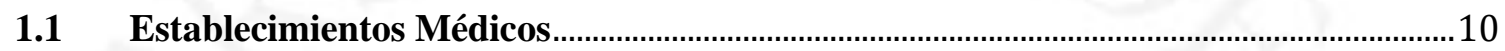

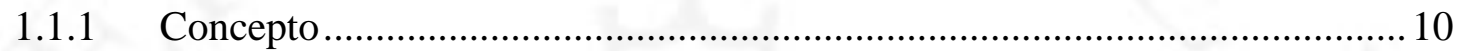

1.1.2 Tesis sobre responsabilidad de establecimientos médicos ........................... 11

1.1.3 Regulación en la normativa peruana ....................................................... 13

1.2 Constitución de empresas médicas creadas con el fin de limitar responsabilidad ....15

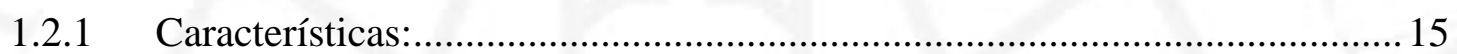

1.2.2 Contratos celebrados con el Establecimiento Médico ................................... 17

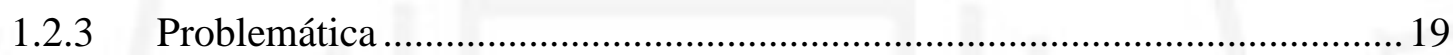

CAPÍTULO II: ALCANCES SOBRE RESPONSABILIDAD CIVIL MÉDICA ....... 20

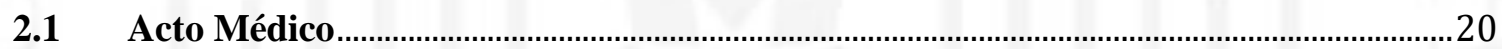

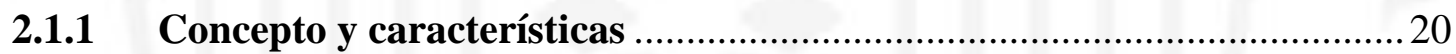

2.1.2 Relación Médico Paciente ....................................................................... 23

2.1.3 Obligación de medios y resultados .........................................................26

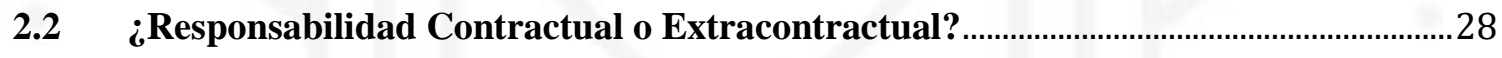

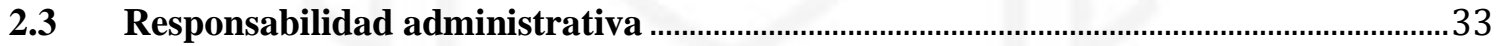

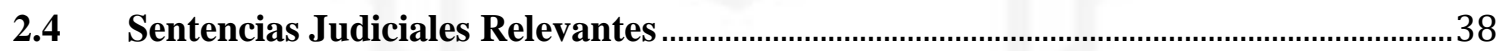

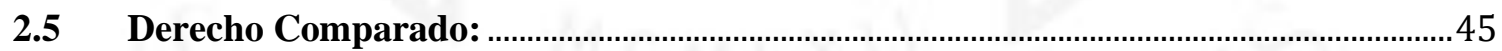

CAPÍTULO III: EL LEVANTAMIENTO DEL VELO SOCIETARIO EN LA

RESPONSABILIDAD CIVIL MÉDICA …....................................................................................5 50

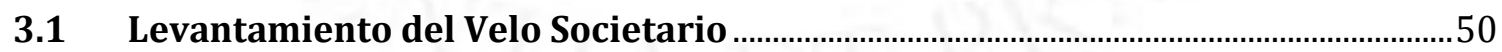

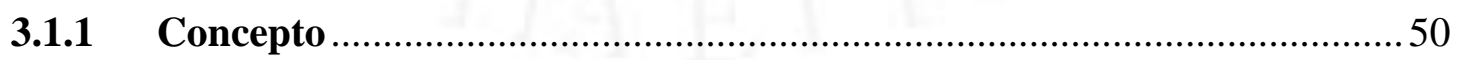

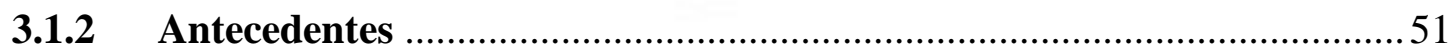

3.1.3 Abuso de Derecho y Fraude a la Ley .......................................................52

3.2 Aplicación de la teoría del Levantamiento del Velo Societario en el derecho laboral: 
CAPITULO IV: PROPUESTA DE APLICACIÓN DE LA TEORÍA DEL LEVANTAMIENTO DEL VELO SOCIETARIO EN LOS CASOS DE RESPONSABILIDAD CIVIL MÉDICA .60 CONCLUSIONES .63 REFERENCIAS 65 


\section{ÍNDICE DE FIGURAS}

Figura 0. 1 Número de empresas de servicios de salud adquiridas por ocho grupos de inversionistas

Figura 1. 1 Cuadro de Niveles de Atención. 


\section{RESUMEN}

En el presente trabajo de investigación, se realiza un análisis de una estrategia usada por los establecimientos médicos hoy en día destinada a evadir o limitar responsabilidad al crear personas jurídicas para relacionarse con los profesionales médicos que integran su plantel. Es así que, añadiendo algunos elementos de la responsabilidad civil, se busca utilizar la figura jurídica del levantamiento del velo societario, haciendo un símil con el uso que de ésta se hace en el derecho laboral, con la finalidad de atribuir responsabilidad a todos los sujetos que se encuentren involucrados en estas complejas relaciones para que el sujeto perjudicado por el evento que causó daño pueda ser debidamente resarcido.

Palabras Clave: Establecimientos Médicos, Responsabilidad, Levantamiento del Velo Societario, Persona Jurídica, Figura Jurídica 


\begin{abstract}
In the present research work, an analysis of a strategy used by medical establishments is carried out today, aimed at evading or limiting responsibility when creating legal persons to interact with the medical professionals that make up their staff. Therefore, adding some elements of civil responsibility, we seek to use the legal figure of the lifting of the corporate veil, making a simile with its use in labor law, in order to attribute responsibility to all subjects that are involved in these complex relationships so that the subject harmed by the event that caused damage can be properly compensated.
\end{abstract}

Keywords: Medical Establishments, Responsibility, Corporate Veil Lifting, Legal Person, Legal Figure. 


\section{INTRODUCCIÓN}

Con el devenir de los años, ha ido proliferando considerablemente la cantidad de establecimientos médicos que existen en la ciudad. Se han ido formando las grandes cadenas o grupos a partir de las aseguradoras que los concentran. Ello viene acompañado de un perfil de paciente cada vez más informado, más educado y conocedor de sus derechos que no vacila en interponer alguna acción o reclamo ante el médico o establecimiento médico que le proporcionó una atención o tratamiento que no fue de su entera satisfacción o en el peor de los casos, le generó grandes daños y perjuicios.

De esta forma, hoy en día es una práctica conocida en los establecimientos médicos el contratar al personal médico que labora en su institución a través de personas jurídicas creadas con el fin de sustentar un vínculo jurídico con el establecimiento que no implique la directa contratación individualmente. La razón: limitar o evadir la responsabilidad de dicho establecimiento.

Estas personas jurídicas creadas por los médicos, usualmente con capitales mínimos y con el único fin de contratar con el establecimiento médico, cuentan con el objeto social de brindar servicios médicos en determinadas especialidades y cuya única relación comercial es normalmente el contrato de arrendamiento o asociación en participación que suscribe con el mencionado establecimiento.

En tal sentido, tenemos que la regulación existente en materia de salud que nos brinda la Ley General de Salud y su reglamento, establecen la solidaridad en la responsabilidad de los establecimientos médicos respecto del personal con el que se vincule en relación de "dependencia" o la "contratación de terceros para la provisión de un servicio". En tal sentido, es necesario develar la estructura ficticia de la persona jurídica que se crea (que como indicamos tiene un capital mínimo y limitada actividad societaria, ya que su fin es contratar con el establecimiento médico) y establecer un criterio jurisprudencial que nos permita proteger a la persona que se ve afectada.

En nuestro país, tenemos grandes grupos empresariales que controlan las principales clínicas existentes en el mercado de la salud privada en nuestro país: Credicorp, el Grupo Breca, Grupo Salud Perú, Mapfre, etc. En los últimos años, se produjo una especie de 
"integración vertical" que hace que las grandes aseguradoras pertenezcan a los mismos dueños que las clínicas más importantes, de acuerdo con el gráfico a continuación.

Figura 0. 1 Número de empresas de servicios de salud adquiridas por ocho grupos de inversionistas

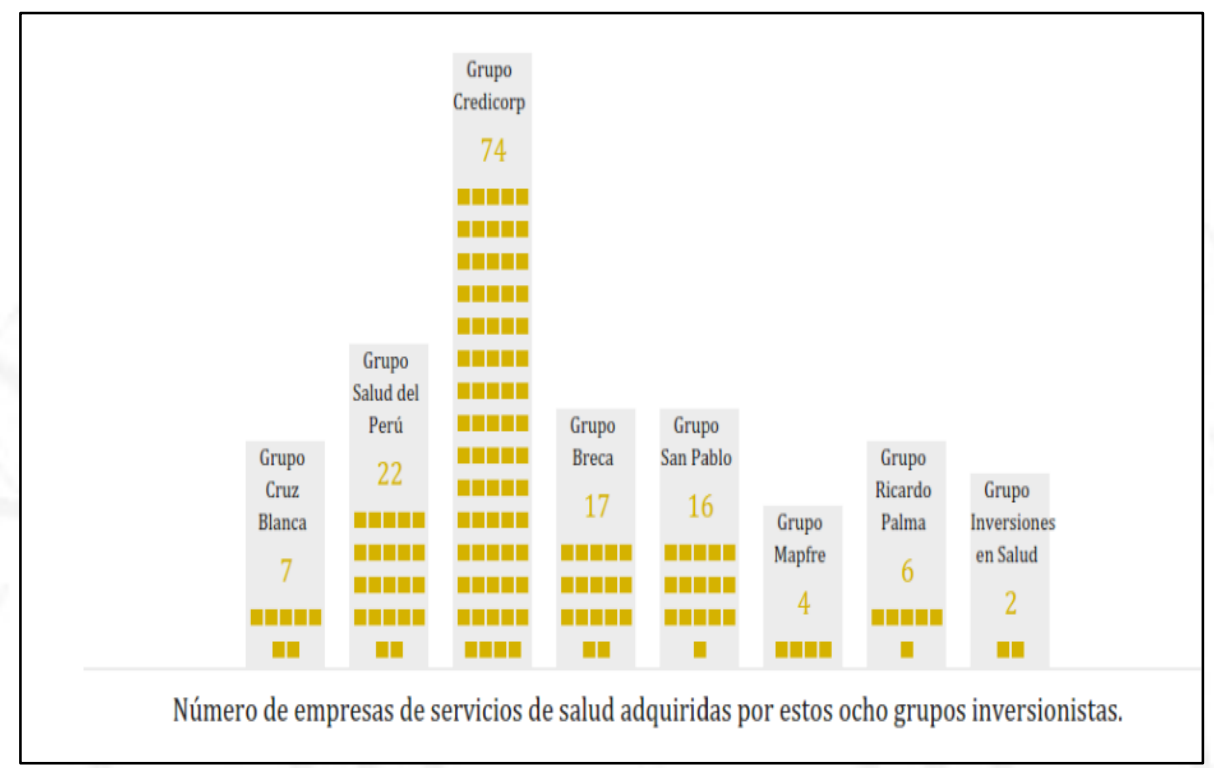

Fuente: Amigos de Ojo Público

Es así que, muchos de estos establecimientos médicos cuentan con las mencionadas modalidades de contratación, y son los grupos empresariales o económicos quienes deben responder sobre ello. He ahí la trascendencia de tener una regulación más precisa sobre esta materia, ya que involucra sectores del mercado importantes.

De esta forma, un mecanismo adecuado para "develar" la figura anteriormente mencionada y que ya viene siento utilizada en materia laboral es la del "levantamiento del velo societario". La misma que, descubre a los socios que se encuentran debajo de la estructura creada con la finalidad de que asuman la responsabilidad de los daños que se han causado. 


\section{CAPITULO I: ESTABLECIMIENTOS MÉDICOS Y EL MECANISMO PARA LIMITAR RESPONSABILIDAD.}

\subsection{Establecimientos Médicos}

\subsubsection{Concepto}

Podemos encontrar una definición en la Ley General de Salud respecto a establecimientos médicos en su artículo $17^{\circ}$ : Entiéndase por establecimientos de salud aquellos que realizan, en régimen ambulatorio o de internamiento, atención de salud con fines de prevención, promoción, diagnóstico, tratamiento y rehabilitación, dirigidas a mantener o restablecer el estado de salud de las personas

Los establecimientos de salud están destinados, por consiguiente, a atender la salud de quien a ellas acude con el propósito de lograr su restablecimiento, así como a prestarles la atención y los cuidados del caso. Para la prestación de sus servicios médico sanitarios, los establecimientos médicos de primer nivel cuentan con un cuerpo médico especializado en la atención de las diversas enfermedades, una apropiada organización administrativa, asistentes o técnicos calificados, un personal de enfermería adecuado, dependencias debidamente equipadas para atender situaciones de emergencia, así como con los aparatos o máquinas más sofisticadas para ofrecer al paciente una eficiente prestación sanitaria, es decir, nos referimos a los equipos para realizar tomografías, resonancias magnéticas, ecografías, tomografías, rayos x y otros altamente sofisticados, destinados a apoyar el diagnóstico médico. (Fernández Sessarego, C., Woolcott Oyague, O, 2018, p. 80). 


\subsubsection{Tesis sobre responsabilidad de establecimientos médicos}

Respecto a la responsabilidad de establecimientos médicos, (Fernández Sessarego, C., Woolcott Oyague, O, 2018), establece las siguientes tesis doctrinarias.

- Tesis de la responsabilidad indirecta de los entes médicos por el hecho de sus auxiliares

La noción principal de esta corriente doctrinaria se apoya en la garantía que aporta el deudor respecto de los hechos de sus auxiliares, representación y teoría del riesgo. No se contempla responsabilidad por hecho ajeno en materia contractual como sí en materia extracontractual.

En este último caso, la responsabilidad extracontractual por hecho ajeno, encuentra su base en la relación de dependencia.

Según la teoría del instrumento, siendo el subordinado un instrumento funcional, los terceros tendrán total acción sobre ellos (desde el punto de vista externo). Asimismo, se explica esta responsabilidad indirecta de los entes asistenciales al ser deudores de la obligación.

\section{- Tesis del Contrato a Favor de Terceros}

Trata de explicar la relación que enlaza al profesional, paciente e institución. La misma es llamada "relación de cobertura". Surgen relaciones del estipulante (centro asistencial) en favor del promitente (médico), generalmente derivado de un contrato de prestación de servicios. En el caso del médico frente al ente, sería el de realizar una prestación en favor de un tercero. En tal caso, tienen derecho a ejecutar las acciones posibles el estipulante y el tercero frente al promitente.

Existe, asimismo, una "relación de valuta" que se da entre estipulante y tercero, este contrato que celebran entre ambos determina lo que el estipulante llega a hacer sobre el beneficiario mediante la celebración del contrato. 
En síntesis, la responsabilidad profesional del médico es directa y contractual ante el paciente por ser este último su acreedor. Asimismo, existe responsabilidad contractual directa del ente asistencial frente al paciente por el contrato celebrado cuyos efectos inciden en el contrato a favor de tercero.

De esta forma, se explica la responsabilidad del ente asistencial debido al deber de seguridad, siendo una obligación accesoria a la principal que es la debida asistencia médica del establecimiento debiendo asegurar un eficiente servicio al paciente a través del personal con el que cumple esta obligación. En ese sentido, probada la responsabilidad del médico, la institución médica tendría que responder, pues existiría incumplimiento del deber tácito de seguridad.

Esta teoría nos direcciona a una responsabilidad objetiva del ente asistencial ya que estaría respondiendo por una conducta de un sujeto independiente como es el médico; sin perjuicio de que exista incumplimiento de las demás obligaciones que asume en función a los servicios que sí presta directamente.

En este caso, el factor de atribución sería "la garantía" de responsabilidad por el hecho de dependiente, debiendo probar la ausencia de culpa de este último para quebrar dicha relación causal.

\section{Relación de Dependencia:}

Existe autonomía técnica y científica de los profesionales liberales respecto a la entidad asistencial. Este argumento implica que el médico no podrá excusar su responsabilidad ya que mantiene discrecionalidad en la toma de decisiones de su actividad profesional.

Ello podría significar un obstáculo para la relación del médico con la entidad asistencial a través de un contrato de trabajo debido a la independencia técnica y científica antes referida; no obstante, el concepto de subordinación jurídica ha sufrido una evolución en la historia, siendo que actualmente se trata de un concepto flexible que se separa cada vez más de la dirección técnica, mientras más se va intelectualizando la labor. (p. 499 - 527) 


\subsubsection{Regulación en la normativa peruana}

La Ley General de Salud regula de manera general el funcionamiento de los establecimientos de salud, indicando en su artículo $37^{\circ}$ que los establecimientos de salud y los servicios médicos de apoyo, cualquiera sea su naturaleza o modalidad de gestión, deben cumplir los requisitos que disponen los reglamentos y normas técnicas que dicta la Autoridad de Salud de nivel nacional relación a planta física, equipamiento, personal asistencial, sistemas de saneamiento y control de riesgos relacionados con los agentes ambientales físicos, químicos, biológicos y ergonómicos y demás que proceden atendiendo a la naturaleza y complejidad de los mismos.

Siendo así, los establecimientos médicos se encuentran categorizados conforme lo indica la NTS $\mathrm{N}^{\circ}$ 021-MINSA dependiendo los servicios que brinden y cuya vigencia es de tres años, de acuerdo al siguiente cuadro:

Figura 1. 1 Cuadro de Niveles de Atención

\begin{tabular}{|c|c|c|}
\hline \multirow{4}{*}{$\begin{array}{l}\text { PRIMER NIVEL DE } \\
\text { ATENCIÓN }\end{array}$} & & Categoría I-1 \\
\hline & & Categoría I - 2 \\
\hline & & Categoría I - 3 \\
\hline & & Categoría I - 4 \\
\hline \multirow{3}{*}{$\begin{array}{l}\text { SEGUNDO NIVEL DE } \\
\text { ATENCIÓN }\end{array}$} & \multirow{2}{*}{$\begin{array}{l}\text { Establecimientos de salud de } \\
\text { Atención General }\end{array}$} & Categoría II - 1 \\
\hline & & Categoría II -2 \\
\hline & $\begin{array}{l}\text { Establecimientos de Salud de } \\
\text { Atención Especializada }\end{array}$ & Categoría II - E \\
\hline \multirow{3}{*}{$\begin{array}{l}\text { TERCER NIVEL DE } \\
\text { ATENCIÓN }\end{array}$} & $\begin{array}{c}\text { Establecimiento de salud de } \\
\text { Atención General }\end{array}$ & Categoría III - 1 \\
\hline & \multirow{2}{*}{$\begin{array}{l}\text { Establecimiento de salud de } \\
\text { Atención Especializada }\end{array}$} & Categoría III-E \\
\hline & & Categoría III-2 \\
\hline
\end{tabular}

Fuente: Ministerio de Salud 
De esta forma, podemos ver que la Ley General de Salud precisa la responsabilidad que tienen los establecimientos médicos en caso de las actividades negligentes o imprudentes de los profesionales que ahí se desempeñan en su artículo $48^{\circ}$, indicando que el establecimiento de salud o servicio médico de apoyo es solidariamente responsable por los daños y perjuicios que se ocasionan al paciente, derivados del ejercicio negligente imprudente o imperito de las actividades de los profesionales, técnicos o auxiliares que se desempeñan en éste con relación de dependencia. Es exclusivamente responsable por los daños y perjuicios que se ocasionan al paciente por no haber dispuesto o brindado los medios que hubieren evitado que ellos se produjeran, siempre que la disposición de dichos medios sea exigible atendiendo a la naturaleza del servicio que ofrece.

La norma precisa que debe existir una "relación de dependencia", sin extenderse más allá de la connotación que tiene este concepto tomado del derecho laboral.

Así, "la "autonomía" de la responsabilidad de las clínicas se basa, principalmente, en la regla de la responsabilidad obligativa del deudor por hechos de los auxiliares que utiliza en el cumplimiento. Según esta regla, también de origen alemán, pero reconocida en las codificaciones de Italia y Perú, el deudor es responsable frente al acreedor por los hechos dolosos o culposos de aquellas personas de cuya actividad se vale para proceder al cumplimiento:

La entidad de cuya organización forma parte el médico -apunta una renombrada civilista- responde de los daños porque en virtud de la normativa contractual el hecho del galeno es directamente atribuible a ella. Se trata de una responsabilidad que se funda en la idea de que el deudor de la prestación debe garantizar al acreedor por el obrar de las personas de las cuales se vale en el cumplimiento de la obligación asumida contractualmente, así como en la ajenidad del acreedor a la elección de los auxiliares.

El paciente - especifica otro autor-espera un resultado útil de la prestación sanitaria pero no respecto del médico, sino de la estructura sanitaria a la cual ha requerido, y de la cual ha obtenido, la prestación. Mientras el médico desarrolla su actividad frente al paciente, 
se limita a realizar la relación obligatoria, pero como auxiliar del establecimiento de salud, el cual (...) responde de los hechos dolosos o culposos del primero. Y el auxiliar, como tal, no es sujeto pasivo de una relación obligatoria autónoma frente al acreedor: él sólo es, o puede ser, aquel mediante cuyo obrar el deudor ejecuta la prestación. (como se citó en Leysser León Hilario, 2017, p. 857-858)

De esta forma, la redacción de la norma supone que exista una relación de dependencia que habría que delimitar o precisar puesto que trae consigo muchas interrogantes a la mesa, ya que los casos son absolutamente diversos, así como las interpretaciones.

Ahora bien, según doctrina mayoritaria, el establecimiento médico tendría una relación contractual con el paciente, lo cual implicaría que se apliquen las reglas de la responsabilidad contractual para el caso de prestaciones ejecutadas por terceros, en el cual la responsabilidad es absolutamente atribuible al establecimiento. No obstante, la Ley General de Salud nos habla de solidaridad, figura regulada en el sistema de responsabilidad extracontractual, respecto de los daños que realiza el subordinado.

\subsection{Constitución de empresas médicas creadas con el fin de limitar responsabilidad}

Los establecimientos médicos se vinculan con empresas médicas creadas por médicos (usualmente de la misma especialidad) para buscar limitar responsabilidad a través de distintas figuras contractuales que les permita tener una relación lo más "independiente" posible.

En tal sentido, a continuación, nombraremos las características más importantes de las sociedades que se constituyen, así como las figuras contractuales más usadas, para finalmente señalar qué problemática conlleva esta situación.

\subsubsection{Características:}

En primer lugar, se establece la creación de personas jurídicas distintas del establecimiento médico constituidas por médicos de la misma especialidad a fin de contratar con el establecimiento médico para desarrollar sus servicios en dicha entidad. 
Así, tenemos que los elementos de dichas personas jurídicas tienen las siguientes características:

- Capital:

Usualmente, hablamos de capitales muy pequeños que no comprometan mucho a los socios que la constituyen pues no existe mayores actividades que se vaya a realizar al interior de la empresa que requiera un alto capital, básicamente se emplea un monto referencial para mantener la empresa.

- Socios o titular:

Este tipo de empresas pueden estar conformadas tanto por un solo titular, como por un grupo de médicos de la misma especialidad que se agrupen con la finalidad de brindar atención médica.

En el caso que sea sólo un médico titular que conforme una EIRL, generalmente es el único médico que brindará atención, es decir no existirán médicos "subordinados" al primero. En este caso, es mucha más clara la relación del médico con el establecimiento.

Cuando son un grupo de médicos, tienen la misma especialidad y generalmente adoptan la forma de sociedad anónima cerrada. No obstante, en ese caso usualmente existen más médicos que prestan servicio en el establecimiento, pero bajo contrato y órdenes de la sociedad creada; es decir, se encuentran bajo su subordinación, aunque con ciertos matices, pudiendo encontrarse o no en la planilla de dicha empresa.

\section{- Objeto}

La Sociedad o empresa que se cree bajo este ámbito, tendrá como objeto la prestación de servicios médicos como es lógico. No obstante, se puede establecer una diferencia en este caso, ya que algunas sólo prestarán dicho servicio en el establecimiento médico y esto es insertado en el objeto social, con lo cual, en mi opinión, se deja más claro el hecho de que fue creada sólo para poder operar en éste.

En otros casos, el objeto si será más abierto, no habiendo una limitación, sobre dónde llevar a cabo la prestación de servicios médicos.

- Actividad de la Persona Jurídica 
Respecto a la actividad de la persona jurídica, ésta después de iniciar con la constitución de la misma y nombramiento de representantes legales (que usualmente es únicamente el gerente general, uno de los socios), no realiza mayores actividades.

En ocasiones, existen cambios de gerente general o nombramiento de algún apoderado adicional debido a la necesidad.

Lo que sí es frecuente son las compras de acciones debido al cambio de socios por retiro de los mismos y que generalmente debe ir acompañada de previas autorizaciones por el establecimiento médico, ya que inicialmente contrató con determinadas personas. El establecimiento médico normalmente tiene preferencia para la compra de dichas acciones.

Fuera de estas situaciones, no hay mayor actividad realizada por la empresa que implique un desarrollo o crecimiento de ésta, salvo por las labores administrativas y contables necesarias para efectos tributarios.

\subsubsection{Contratos celebrados con el Establecimiento Médico}

Una vez creada la empresa, ésta debe vincularse con el establecimiento médico con el fin de que los médicos puedan prestar efectivamente sus servicios. A continuación, se nombran y explican los típicos contratos celebrados para estos fines, los cuales tienen en común que contienen cláusulas que deslindan ampliamente la responsabilidad por negligencias o impericias en el ejercicio de la práctica médica, "excluyendo" al establecimiento médico del mismo.

- Arrendamiento:

En este caso, el establecimiento médico celebra un contrato de arrendamiento con la persona jurídica creada respecto de un determinado espacio o consultorio a cambio de una renta pactada, que generalmente es un porcentaje de las ventas de los servicios médicos ofrecidos, no siendo ésta lógicamente la única opción.

Adicionalmente a ello, este contrato incluye una serie de obligaciones para cada parte que no sólo se remiten a lo concerniente al espacio arrendado, sino también a la organización que tendrá la persona jurídica al interior de dicho espacio, así como una serie de disposiciones que tienen que ver con el funcionamiento del 
establecimiento médico, en el cual se establece prohibiciones y sujeciones a horarios, formas de proceder, montos mínimos a ser cobrados, tarifas establecidas, entre otros.

\section{- Asociación en Participación}

Otro tipo de contrato utilizado en los establecimientos médicos con las personas jurídicas creadas son las asociaciones en participación que implican la sinergia de ambas personas jurídicas para poder desarrollar un negocio en común, prestando el establecimiento médico toda la gestión del negocio, espacio, implementos y siendo la persona jurídica creada quien preste el servicio médico en sí.

En este caso, las participaciones de ambas partes se establecerán y calcularán dependiendo de los resultados del negocio planteado.

Se generan obligaciones para ambas partes desde el punto de vista de la función que cada uno cumplirá; sin embargo, se establecerá claramente las limitaciones que la persona jurídica tendrá en relación al funcionamiento del establecimiento médico.

- Tercerización

La tercerización es otro mecanismo utilizado para tener la prestación del personal médico en el establecimiento médico. No obstante, éste es un mecanismo más vinculado al tema laboral.

La persona jurídica creada actuará como empresa tercerizada en la prestación de los servicios médicos que el establecimiento médico preste. Raramente la contraprestación es un monto fijo ya que justamente lo que se busca es generar la mayor cantidad de venta en servicios médicos y es por ello que se fijarán porcentajes para cada parte.

Esta tercerización implicará, como es lógico, el destaque de personal médico hacia las instalaciones del establecimiento médico siendo que la naturaleza de este tipo de contrato implica la no subordinación al establecimiento médico sino a la empresa tercerizadora, lo cual en la práctica no suele ocurrir así. 


\subsubsection{Problemática}

La creación de una persona jurídica no constituye un ilícito; sin embargo, ciertos beneficios que se generan al constituirla traen como consecuencia que, se puedan desconocer derechos a sujetos perjudicados; y es ahí, en donde el derecho proporciona herramientas para restablecer esta situación.

Es así que, los establecimientos médicos utilizan el argumento de los médicos que laboran en su institución no se encuentran vinculados bajo relación de dependencia ya que los mismos pertenecen a otra persona jurídica que utiliza sus instalaciones a través de una relación contractual.

En tal sentido, dichas personas jurídicas, como se ha podido explicar líneas arriba, cuentan con patrimonios muy pequeños que difícilmente podrían cubrir las expectativas del perjudicado, ya que han sido creadas con finalidades específicas, siendo necesario atribuir responsabilidad tanto al establecimiento médico como develar las personas que conforman la estructura creada para deslindar responsabilidad. 


\section{CAPÍTULO II: ALCANCES SOBRE RESPONSABILIDAD CIVIL MÉDICA}

\subsection{Acto Médico}

\subsubsection{Concepto y características}

Existe amplia literatura que nos permite definir el acto médico; siendo su concepto una mezcla de conceptos jurídicos y humanistas.

Siendo así, "el acto médico es toda acción o disposición que realiza el médico en el ejercicio de su profesión médica.” (Varsi-Rospigliosi, 2006, p. 56).

Lee (2005) manifiesta que el acto médico es un proceso complejo. Se trata de un acto humano en donde dos personas se relacionan entre sí, por una parte, el profesional de la medicina y por el otro el paciente. En esta relación, coexisten elementos explícitos e implícitos y se evalúa, como en cualquier otro tipo de relación, en función de sus resultados. (p.6)

Podemos decir que el acto médico implica que el médico despliegue todo el conocimiento adquirido por los estudios que ha realizado, así como por la experiencia que éste acumula a lo largo de sus años de práctica a fin de encontrar la posible solución a las dolencias del paciente, situación que, al colocarse en el ámbito más sensible del ser humano, lo convierte en un acto profesional aún más complejo.

Desde siempre el ser humano ha buscado que el profesional médico resuelva sus dolencias de salud, siendo que actualmente las personas cuentan con una mayor cantidad de información que les permite cuestionar los actos que dichos profesionales ejercen sobre ellos.

Dicho esto, según Guzmán y otros (1994) “el "acto médico" es un hecho del hombre específicamente capacitado en esta ciencia, que acarrea consecuencias porque se realiza voluntariamente y tiene como "objeto" la vida o la salud de otro hombre (paciente), de manera que el resultado del actuar del médico siempre tendrá que ver con la ley, por incidir 
sobre un "sujeto de derecho"; por afectar los derechos de otro hombre que se ha puesto en sus manos.

Como mencionaba anteriormente, el proceso se torna complicado desde que la materia de trabajo de dicho profesional es la salud y muchas veces, la vida del paciente.

Adicional a ello, el profesional que ejerce el acto médico debe estar previsto de la autorización legal que lo faculta a ejercer tales actos. Asimismo, debe entenderse que el "Acto Médico" no se refiere a cualquier acto que realice el médico sino específicamente a los que se realicen en su ejercicio profesional.

No obstante, la definición de acto médico no debería circunscribirse únicamente a aquellos casos en los que se busca recuperar la salud del paciente, ya que podrían existir intenciones meramente preventivas. Así, curar, no significa necesariamente recuperar la salud del paciente, sanar al enfermo, a veces ello resulta imposible no obstante la aplicación de todos los recursos puestos a disposición del médico por la ciencia, así como a todos los esfuerzos por él desplegados, de ahí que, en algunas circunstancias, lo único que se puede conseguir es tratar al paciente sin lograr su curación, es decir, tan solo, aliviar su mal, esta percepción del acto médico es importante para los fines de determinar el cumplimiento de las obligaciones del médico (...) (Fernández Sessarego, C., Woolcott Oyague, O, 2018, Tomo 1, p.110).

Por otro lado, tenemos que el Reglamento de la Ley de Trabajo Médico D.S. N $024-$ 2001-SA en su artículo $5^{\circ}$ define al acto médico como toda acción o disposición que realiza el médico en el ejercicio de la profesión médica. Ello comprende, los actos de diagnóstico, terapéutica y pronóstico que realiza el médico en la atención integral de pacientes, así como los que se deriven directamente de éstos. Los actos médicos mencionados son de exclusivo ejercicio del profesional médico.

Esta definición tiene concordancia con lo expuesto anteriormente; en el sentido que, vincula la acción del médico con su actividad profesional; no obstante, no menciona las actividades preventivas que puede realizar el médico con el paciente. 
Los presupuestos para el ejercicio médico son:

- La salud como bien jurídico tutelado: de producirse un daño en la salud del individuo, éste será sancionado y reparado. Es un bien que no tiene cuantificación económica, no siendo parte del comercio, es imprescriptible, inalienable. La salud interesa y compromete al orden público; es decir, es de interés general como profesión y actividad social.

- Respeto de la dignidad humana: La base de los derechos humanos es la dignidad, siendo uno de los aspectos más importantes de la relación médico - paciente. Asimismo, es parte del juramento hipocrático del médico. (Yungano, 1986, p.5558)

Según Varsi-Rospigliosi (2006), las características del acto médico son:

- Profesionalidad:

Sólo el profesional de la medicina puede efectuar un acto médico. Esto quiere decir que para el ejercicio de la actividad sanitaria se necesita de la certificación y estar registrado en el Colegio profesional correspondiente:

- Ejecución regular o típica:

Su ejecución se realiza conforme a la denominada Lex Artis ad hoc, de manera que, existiendo una técnica a través de la que se obtendrán los resultados, es preciso contar con principio y lineamientos que sirvan de pauta de trabajo.

- Licitud:

El acto médico está sustentando en la ley. Existe normatividad que regula la actividad médico-sanitaria y es en base a ella que debe desarrollar el quehacer profesional. (p.57)

Sobre lo indicado por Varsi - Rospigliosi, es importante resaltar que, de acuerdo a la característica de ejecución regular o típica, implica que los médicos cuentan con protocolos de actuación que determinen que no se remite al mero criterio del profesional, sino que sirven de guía para buscar la solución o diagnóstico al paciente. 
De esta forma, también podemos hablar de las siguientes características del Acto Médico:

- Profesionalidad: sólo ejecutable por el profesional médico; sujeto a las normas de excelencia profesional vigentes (lex artis ad hoc), teniendo en cuenta el desarrollo científico, complejidad del acto médico, disponibilidad de equipo y medios de trabajo, y las circunstancias específicas de la enfermedad del paciente;

- Beneficiencia: búsqueda del bien del paciente. No maleficencia (primum non nocere), obligación de no producir daño; Prevenir el daño; eliminar lo que está haciendo daño y Promover lo que hace bien al paciente. (Vera Carrasco, 2013) El principio o característica de Beneficencia y No Maleficencia es bastante utilizado en el campo de la medicina, ya que, si un evento produce mayor daño al paciente que un beneficio para su salud, entonces el mismo no será puesto en marcha por el médico tratante. Se buscará siempre la mayor ventaja para el paciente.

\subsubsection{Relación Médico Paciente}

La relación médico paciente ha venido sufriendo una transformación progresiva a lo largo de los años. Ello debido a que, la figura médica surge con una suerte de "divinidad" aparejada. En tal sentido, no era una situación usual que existieran reclamos por parte de los pacientes hacia los médicos.

De esta forma, la relación médico paciente históricamente asimétrica tiende, en nuestro tiempo, a asumir una de carácter horizontal, según lo denotan las pertinentes disposiciones del derecho comparado, las que se sustentan en la nueva realidad constitutiva del ser humano, en tanto un ser de libertad, así como en los principios éticos que regulan las relaciones humanas. (Fernández Sessarego, 2011, p. 53)

Es así que, se puede justificar esta tendencia horizontal en la relación médico paciente a los nuevos conceptos que se manejan sobre lo que significa la persona basada siempre en el concepto de libertad y derechos fundamentales que obliga a esta relación a cambiar y tornarse más equitativa. Como indica Fernandez Sessarego, (2011), la nueva relación de simetría entre el médico y el paciente obliga a aquél, además a informar a este sobre las alternativas posibles al tratamiento recomendado, si las hubiere, y sobre cuáles serían las posibilidades de éxito al utilizarse algunas de ellas. (p. 54) 
Siendo así, la "relación médico paciente constituye no sólo el presupuesto de la semiología en cuanto ciencia que estudia los signos y los síntomas de las enfermedades, sino elemento esencial para una adecuada asistencia y tratamiento del enfermo." (Seijas Rengifo, 2001, p.33)

De esta forma, la relación médico - paciente, en virtud de lo expuesto, se desarrolla en dos niveles perfectamente diferenciados. En el primero de ellos, los sujetos de la relación jurídica son el médico, de una parte, y el paciente, de la otra. Se trata de una relación de conductas humanas intersubjetivas, donde cada uno de dichos sujetos cumple un determinado rol en cuanto titular de derechos y de deberes. Cada uno está instalado, por consiguiente, en una determinada "situación jurídica subjetiva. En un segundo nivel la relación jurídica se despliega, cada vez con mayor intensidad, entre el paciente y el establecimiento de salud al cual recurre el enfermo. Este último, se constituye como una empresa, es decir, como una organización de personas, donde cada una de estas cumple una específica función. La empresa médica, tanto pública como privada, cualquiera sea su modalidad, tiene a su cargo diversas prestaciones de salud. (Fernández Sessarego, C., Woolcott Oyague, O, 2018, p. 356-357).

Según Seijas Rengifo (2001), la relación médico-paciente puede asimilarse a varias figuras jurídicas como:

- Mandato: Se asimiló a esta figura ya que se consideró que el objeto del contrato de servicios médicos no puede contener una prestación monetaria. Sin embargo, se considera que el mandato no es una figura gratuita y supone una retribución, además de que se entiende que el mandatario ejecutará actos jurídicos por cuenta del mandante; por lo que, no sería la figura más adecuada.

- Locación de servicios: Se podría considerar esta figura ya que una persona prometería a otra la realización de un servicio, sin tomar en cuenta el resultado, a cambio de una contraprestación.

- Locación de Obra: A diferencia de la figura anteriormente expuesta, en este caso si se esperaría un resultado. No obstante, el hecho de que la esencia de la relación médico-paciente considere el cumplimiento de una obligación de medios la hace poco viable.

- Contrato innominado: Algunos autores la encuadran en esta figura porque consideran que no existe una figura exacta. 
- Contrato variable o múltiple: Ya que combinaría dos tipos de contratos y variaría de acuerdo al contenido de la prestación médica.

- Asistencia Médica: Encajaría más favorablemente en esta figura ya que debido a sus características especiales es necesario que la misma deba ser más específica. Tiene las siguientes características:

- Intuito Persona: De carácter relativo, ya que no siempre hay una exclusividad por determinado profesional médico.

- Bilateral: ambos cumplen con responsabilidades.

- Oneroso: generalmente implica una contraprestación.

- $\quad$ Carácter civil

- Conmutativo: Debe haber una reciprocidad, cada parte tiene un beneficio, pero el mismo es aleatorio.

- Consensual: queda concluida mediante el consentimiento.

- $\quad$ Principal: puede haber contratos accesorios (auxiliares) (p. 37-38)

Asimismo, la relación médico-paciente tiene como elemento esencial el cuidado de la salud. Se presenta como una relación jurídica de prestación de servicios por la que el profesional de la salud atiende a quien se lo solicita, celebrándose expresa o tácitamente, el contrato de asistencia médica. (como se citó en Varsi-Rospigliosi, 2006, p.149)

De acuerdo a lo indicado por Yungano, (1986), los deberes para ambas partes derivadas de la relación médico-paciente:

- Médico:

- Historia Clínica: En donde se consignará el diagnóstico, pronóstico, tratamiento y evolución del paciente.

- $\quad$ Asistencia del Paciente: Significa velar por la salud del paciente, siendo el acto médico por excelencia.

- Diagnóstico: El médico realiza un diagnóstico de la enfermedad a partir de la revisión del paciente y los exámenes complementarios que se realicen. Éste es sustento del pronóstico y tratamiento del paciente.

- Tratamiento: El tratamiento debe responder al estado y características del paciente y tiene que ser: 1) Autorizado y/o admitido por la autoridad sanitaria. 2) adecuado al enfermo y enfermedad 3) la respuesta debe ser correlativa al estado del paciente. 
- Deber de informar: La información debe ser leal, clara, inteligible y adecuada con el estado y nivel del paciente.

- La derivación del paciente: Si el médico no puede atender al paciente o no es su especialidad, deberá enviarlo al médico pertinente.

- $\quad$ El Secreto Médico: Tiene que ver con el vínculo que se genera con el paciente en cuanto a la relación que desarrollan. Se trata de un tema de confianza, sólo podrá ser revelado cuando el paciente lo autoriza o cuando la ley así lo ordena.

- Certificado Médico: Se consignan los datos del paciente y la incapacidad con la que cuenta.

- Paciente:

- Lealtad de información: El paciente debe ser sincero en cuanto a la información que brinda al médico. El médico debe utilizar la técnica adecuada para obtener dicha información.

- Cumplimiento de plan terapéutico: Éste debe ser claro, sin márgenes de error o dudas en cuanto a lo que deba formularse por escrito.

- Nueva Consulta: Si el paciente acude a otro especialista, debe comunicarlo al médico.

- Pago de Honorarios: Como contraprestación de la obligación de Asistencia Médica.

- Paciente afiliado a institución intermedia: Debe pagar las cuotas pactadas en el establecimiento. (p. 116-126),

\subsubsection{Obligación de medios y resultados}

- Obligación De Medios

En este tipo de obligación, el médico se obliga a procurar actuar de forma determinada para lograr un fin; sin embargo, no se asegura o promete conseguir un resultado determinado.

Es así que, en este caso, según Fernández Sessarego, C., Woolcott Oyague, O. (2018) el médico se compromete a procurar, sin omisiones, todo lo que la ciencia médica pone a su alcance para obtener una mejoría en la salud del paciente. El médico se obliga no a curar necesariamente al enfermo sino a proporcionarle 
diligentemente todos los cuidados y atenciones que requiera según el estado de la ciencia y la técnica médicas. En otros términos, el médico no se obliga a obtener, siempre y necesariamente un resultado que sería el de curar al enfermo. $(\ldots)$

Tratándose de una obligación de medios o de actividad, es el acreedor de esta obligación el que debe aportar la prueba de que el deudor de la misma no ha actuado conforme a la lex artis, es decir, que no ha cumplido con desarrollar una conducta de acuerdo al estándar requerido en el caso específico de que se trate." (p 203-204)

- Obligación de resultados:

La obligación de resultados implica que el médico asegura un resultado determinado; es decir, no se evalúa el procedimiento para conseguirlo sino efectivamente conseguirlo; siendo que no de hacerlo, se genera el incumplimiento.

En este caso como indica Fernández Sessarego, C., Woolcott Oyague, O. (2018) es el profesional médico el que aporta la prueba. Es él el que debe demostrar que el compromiso se cumplió tal como fue ofrecido o, si él no se alcanzó, se debió a causas extrañas a su voluntad como fuerza mayor o caso fortuito o debido a la acción de un tercero. Puede darse también el caso que el paciente no cumplió con las indicaciones impartidas por el médico en el curso del tratamiento (p.204)

Sobre la discusión antes comentada, debe precisarse que la doctrina y jurisprudencia comparada concuerdan en que existen obligaciones de medios y de resultados a cargo de los médicos. Es decir, no existe un criterio único para definir el tipo de obligación que el médico tendría pues ello va a depender del servicio que se encuentre brindando el médico; así si, por ejemplo, estamos hablando de un servicio de laboratorio médico, el paciente espera que el médico le brinde un resultado específico que es el informe médico con los resultados correctos. Por otro lado, existen otros servicios médicos en los cuales el médico no puede prometer un resultado determinado; sin embargo, sí deberá observar toda la diligencia posible para ejecutar dicho servicio.

En tal sentido, "si bien es cierto que, en general, en la relación médico-paciente predomina una obligación de medios, no debe dejarse absolutamente de lado el resultado por todos perseguido, el mismo que ilumina los medios al otorgarles un sentido. Es decir, 
los medios sólo pueden ser apreciados a partir y en función del resultado obtenido o que pudiera haberse logrado. Cuando se habla de resultado en este caso, aludimos al interés primario del acreedor, es decir el interés que espera satisfacer, pero que en una obligación de medios no está in obligatione, vale decir, no es exigible jurídicamente, aunque sí sea el referente de la prestación del deudor.” (Fernández Sessarego, C., Woolcott Oyague, O, 2018, p. 226)

\section{$2.2 \quad$ ¿Responsabilidad Contractual o Extracontractual?}

El tema de la responsabilidad médica es complejo debido a que en la actualidad implica más actores que simplemente el médico, además de la evolución que ha sufrido la relación médico-paciente, en donde el paciente tiene un mayor conocimiento al respecto.

Así, en nuestros días no sólo se debe tener en consideración, exclusivamente como antaño, la relación entre el médico y el paciente sino que nos debemos enfrentar a un complejo de relaciones en donde, aparte de aquellas de carácter interpersonal, se constituyen aquellas otras donde el sujeto se convierte en destinatario de prestaciones médico - sanitarias ofrecidas por los establecimientos de salud. En estas últimas relaciones identificamos prestaciones de diverso tipo, ya sean ellas de carácter preventivo, de diagnóstico, terapéuticas, quirúrgicas, asistenciales, de rehabilitación, o relativas a la atención proveniente de resultados de laboratorio o de diferentes apoyos técnicos, radiografías, ecografías, resonancias magnéticas, tomografías axiales y otras relaciones vinculadas con la prestación médica integral.

\section{$(\ldots)$}

De otro lado, los establecimientos de salud brindan, además, alojamiento y atención al paciente, así como un servicio de alimentación adecuado a su estado de salud. Estas prestaciones se llevan a cabo por un cuerpo de enfermeras y otros dependientes administrativos de dichos establecimientos de salud. Es este cúmulo o plexo de relaciones y no sólo aquellas meramente interpersonales-las que, muchas veces, deben tomarse en cuenta en la actualidad para determinar los alcances de la responsabilidad médica." (Fernández Sessarego, C., Woolcott Oyague, O, 2018, p. 166).

Es así que al ser la relación médico-paciente concebida como contrato de asistencia médica, su incumplimiento deviene en responsabilidad para el profesional médico. 
No existe un consenso respecto al carácter de la responsabilidad civil médica; es decir, si la misma es contractual o extracontractual. No obstante, la tendencia actualmente es que la misma deviene de una responsabilidad contractual pero que en ocasiones existen circunstancias en la que es extracontractual. Así, "se advierte que la relación jurídica contractual entre médicos y pacientes puede surgir sobre la base de un acuerdo, expreso o tácito, de voluntades. Es decir, se trata de una situación donde ambas partes han querido dicha relación y sus consiguientes efectos, por lo que convienen en que los primeros presten atención médica a los segundos y estos, a su vez, la retribuyan a través de un honorario. Pero puede ocurrir lo contrario, es decir, que no exista un acuerdo previo de voluntades; no obstante lo cual el médico, atendiendo a un mandato ético-legal, debe prestar asistencia, por ejemplo, a un enfermo que ha perdido el conocimiento y requiere urgente socorro médico. En el primer caso, que es el común, se crea entre médicos y pacientes una relación jurídica de naturaleza contractual $\mathrm{y}$, en el segundo caso, surge una relación de carácter extracontractual. (Fernández Sessarego, C., Woolcott Oyague, O, 2018, p. 480).

Así, León Hilario (2017) afirma que: (...) son particulares de ordenamientos donde la carga probatoria en la responsabilidad contractual y extracontractual se distribuye tradicionalmente: con menor gravosidad para el accionante en la primera, no así en la segunda, donde quien pretende el resarcimiento tiene que probar, como regla, el criterio de imputación, junto con los demás presupuestos de la responsabilidad. En nuestro Código Civil, en cambio, el traslado de la carga probatoria (“del descargo por falta de dolo o culpa") al propio autor del daño en la responsabilidad extracontractual, peculiaridad que singulariza la experiencia peruana ante los analistas extranjeros, obliga a opinar favorablemente respecto de la "contractualización" de la responsabilidad "médica", fenómeno que, por lo demás, ha terminado imponiéndose también, aunque con mayor dificultad, en los ordenamientos ligados a las reglas probatorias clásicas. (p.852)

\section{- Responsabilidad contractual}

Esta tesis sostiene que existe un acuerdo de voluntades entre el médico y el paciente, que generalmente es tácito. No obstante, podría el médico brindar el servicio de manera individual o a través de un centro de salud, de ello va a depender entre quiénes se celebre la relación jurídica. En este último caso, se brindan más prestaciones además de los servicios médicos. De esta forma, pueden existir varios contratos en una sola relación, debiendo verse el caso en concreto para la determinación de la responsabilidad. 
Las normas que nuestro Código Civil a la institución de la responsabilidad contractual son:

Artículo $1314^{\circ}$.- Inimputabilidad por diligencia ordinaria

Quien actúa con la diligencia ordinaria requerida, no es imputable por la inejecución de la obligación o por su cumplimiento parcial, tardío o defectuoso. Artículo $1318^{\circ}$.- Dolo

Procede con dolo quien deliberadamente no ejecuta la obligación.

Artículo $1319^{\circ} .-$ Culpa inexcusable

Incurre en culpa inexcusable quien por negligencia grave no ejecuta la obligación.

Artículo $1320^{\circ}$.- Culpa leve

Actúa con culpa leve quien omite aquella diligencia ordinaria exigida por la naturaleza de la obligación y que corresponda a las circunstancias de las personas, del tiempo y del lugar.

Artículo $1321^{\circ}$.- Indemnización por dolo, culpa leve e inexcusable

Queda sujeto a la indemnización de daños y perjuicios quien no ejecuta sus obligaciones por dolo, culpa inexcusable o culpa leve.

El resarcimiento por la inejecución de la obligación o por su cumplimiento parcial, tardío o defectuoso, comprende tanto el daño emergente como el lucro cesante, en cuanto sean consecuencia inmediata y directa de tal inejecución Si la inejecución o el cumplimiento parcial, tardío o defectuoso de la obligación, obedecieran a culpa leve, el resarcimiento se limita al daño que podía preverse al tiempo en que ella fue contraída.

Artículo $1325^{\circ}$.- Responsabilidad en obligaciones ejecutadas por tercero

El deudor que para ejecutar la obligación se vale de terceros, responde de los hechos dolosos o culposos de éstos, salvo pacto en contrario.

En este último artículo, vemos que el deudor es responsable de manera exclusiva por lo hechos dañosos y culposos que realice el tercero que los ejecute, siendo que en el caso de establecimientos médicos (cuya doctrina mayoritaria indica es 
una responsabilidad contractual) respondería por las acciones de los médicos que ahí se desempeñan de manera exclusiva.

No obstante, en palabras de Cieza Mora (2013): "De una lectura literal del artículo en comento sería necesario probar, por parte del dañado, el dolo o la culpa del tercero del cual se vale la estructura sanitaria, es decir del médico. Sería mucho más sencillo aplicar el criterio de inversión de la carga de la prueba regulado en el artículo 1969 del Código Civil; sin embargo, estaríamos encuadrados dentro del marco de la responsabilidad extracontractual. Considero que aún estando en aplicación del sistema de responsabilidad contractual debe aplicarse la inversión de la carga de la prueba mediante la utilización de teorías como la causalidad probabilística o la res ipsa loquitur (la cosa habla por sí misma), pues sería totalmente arbitrario exigir al dañado que pruebe el dolo o la culpa del médico o auxiliar cuando lo más probable es que se presente una situación asimétrica. (p.89)

Ahora bien, nuestro Código Civil regula un tipo de responsabilidad especial por prestación de servicios profesionales en su artículo $1762^{\circ}$ :

Artículo $1762^{\circ}$.- Responsabilidad por prestación de servicios profesionales o técnicos

Si la prestación de servicios implica la solución de asuntos profesionales o de problemas técnicos de especial dificultad, el prestador de servicios no responde por los daños y perjuicios, sino en caso de dolo o culpa inexcusable.

Este artículo es particularmente importante ya que la prestación de servicios médicos podría ser tomado como un asunto de "especial" dificultad, concepto que es absolutamente ambiguo y subjetivo ya que cómo podría establecerse un criterio para determinar la complejidad de un asunto técnico o profesional que limite los factores de atribución para determinar la responsabilidad.

\section{- Responsabilidad Extracontractual}

Esta tesis sostiene que la relación entre médico y paciente no constituye un contrato, estas teorías se fundan en que de esta responsabilidad es la ley y no un contrato, asimismo consideran que existe una especial jerarquía y que, por la naturaleza de sus funciones, los médicos asumirían la calidad de "funcionarios públicos". 
En cuando a la naturaleza extracontractual de la relación médico-paciente cabe referirse a la singular posición sostenida por YUNGANO en el sentido que ella, siempre y en todo caso, es de carácter contractual. Considera, en efecto, que no se han juzgado adecuadamente los varios supuestos en los cuales la relación en referencia se ha considerado comúnmente como extracontractual. Así, señala como ejemplo, que cuando el médico presta sus servicios a una persona desconocida que se ha desmayado en la vía pública o ha sido atropellada por un vehículo automotor o se encuentra en estado inconsciente o de shock, la atención del médico se fundamenta en un deber legal que tiene como fuente su juramento profesional. Ello generaría una obligación ex lege, o bien en mérito a una voluntad tácitamente anticipada según la cual en un caso de accidente la persona aceptará los servicios del médico que, ocasionalmente la asista. (Fernández Sessarego, C., Woolcott Oyague, O, 2018, p. 488-489).

Así, nuestro Código Civil regula la responsabilidad extracontactual en el artículo $1969^{\circ}:$

Artículo $1969^{\circ}$.- Indemnización por daño moroso y culposo

Aquel que por dolo o culpa causa un daño a otro está obligado a indemnizarlo. El descargo por falta de dolo o culpa corresponde a su autor.

Asimismo, esta sección establece las disposiciones relativas a la responsabilidad del subordinado:

Artículo $1981^{\circ}$.- Responsabilidad por daño del subordinado

Aquel que tenga a otro bajo sus órdenes responde por el daño causado por este último, si ese daño se realizó en el ejercicio del cargo o en cumplimiento del servicio respectivo. El autor directo y el autor indirecto están sujetos a $\underline{\text { responsabilidad solidaria. }}$

En este último caso, la norma establece la solidaridad de las partes en cuanto al daño causado, lo cual es una diferencia sustancial con la responsabilidad contractual, ya que las consecuencias respecto del perjuicio causado recaen tanto en el autor directo como en el indirecto. 
Es así que la importancia en delimitar si la responsabilidad civil en la prestación de servicios médicos es contractual o extracontractual se debe al tipo de responsabilidad que se atribuirá, siendo la misma solidaria o no dependiendo del caso.

\subsection{Responsabilidad administrativa}

El derecho de consumidor también se ocupa de las relaciones entre consumidores y el médico o establecimientos médicos.

Actualmente, ya no es discutible la calidad de consumidor del paciente, ya que existe una prestación económica a cambio de un servicio realizado por el médico u organización de salud; por lo tanto, es aplicable su legislación.

Es así que, conforme se indica en el Código de Protección al Consumidor, el Consumidor puede definirse como: las personas naturales o jurídicas que adquieren, utilizan o disfrutan como destinatarios finales productos o servicios materiales e inmateriales, en beneficio propio o de su grupo familiar o social, actuando así en un ámbito ajeno a una actividad empresarial o profesional. No se considera consumidor para efectos de este Código a quien adquiere, utiliza o disfruta de un producto o servicio normalmente destinado para los fines de su actividad como proveedor.

De esta forma, al no haber una limitación sobre el producto o servicio referido, el paciente calza en la definición que nos brinda la norma.

No obstante, reconocer que el tema que se plantea no es de fácil solución dada las diversas posturas adoptadas por el derecho comparado, Walter Gutiérrez expresa su adhesión a la posición doctrinaria que considera que el contrato médico, es un contrato de consumo. Estima que esta solución está consagrada por la legislación, refiriéndose a la que estuvo vigente antes de la dación en el 2010 del Código de Protección y Defensa del Consumidor, y que, además, ello resulta conveniente para los pacientes o consumidores de servicios médicos, pues que existen razones para que ello sea así. Cabe señalar que, cuando un médico o una clínica contrata directamente con un paciente se perfecciona siempre un contrato de consumo de servicios médicos-sanitarios. Gutiérrez adhiere a esta posición en cuanto estima que "militan" en esta postura razones atendibles. (como se citó en Fernández Sessarego, C., Woolcott Oyague, O, 2018 p.45, 48) 


\section{- Código de Protección y Defensa del Consumidor:}

El Código de Protección y Defensa del Consumidor establece un capítulo destinado a productos y servicios de salud, estableciendo en el artículo 67.3 que: Los establecimientos de salud y los servicios médicos de apoyo tienen el deber de informar al consumidor, a sus familiares o allegados sobre las características del servicio, las condiciones económicas de la prestación y demás términos y condiciones, así como los aspectos esenciales vinculados al acto médico.

El artículo 67.3 realiza una precisión sobre el deber de información que tienen los establecimientos médicos. Este deber se encuentra presente en cualquier bien o servicio que se comercialice, siendo que, dado las características especiales del bien protegido en este caso, el acto médico debe ser adecuadamente informado en todos sus niveles.

El artículo en mención no se refiere al médico en particular; no obstante, estos últimos también contratan directamente con el paciente y mantienen el mismo deber de información; por lo que, considero oportuno que se hubiese tenido que incluir la mención al médico, en mayor medida si se refieren específicamente al acto médico.

Así, como indica Fernández Sessarego, C., Woolcott Oyague, O, dentro del esquema del dispositivo legal protector de los consumidores, los médicos asumen, por lo tanto, la categoría jurídica de “proveedores" de servicios médicos en tanto no se encuentren en relación de dependencia, según la definición de "servicio" que ofrece el Código. Como proveedores, los médicos pueden incurrir en las infracciones administrativas que contempla el artículo $108^{\circ}$ del Código del Consumidor y ser pasibles, en consecuencia, de las sanciones administrativas contempladas en este cuerpo legal, impuestas por un órgano administrativo (Indecopi) competente para el efecto de realizar las acciones tendentes a la protección de los consumidores. (p. 82, 2018)

El artículo $68^{\circ}$ menciona la responsabilidad en la prestación de servicios indicando que: $68.1 \mathrm{El}$ establecimiento de salud es responsable por las infracciones al presente Código generadas por el ejercicio negligente, imprudente o imperito de las actividades de los profesionales, de los técnicos o 
de los auxiliares que se desempeñen en el referido establecimiento, sin perjuicio de las responsabilidades que les correspondan a estos.

68.2 El establecimiento de salud también es responsable por los actos de los profesionales que de manera independiente desarrollen sus actividades empleando la infraestructura o equipos del primero, salvo que el servicio haya sido ofrecido sin utilizar la imagen, reputación o marca del referido establecimiento y esa independencia haya sido informada previa y expresamente al consumidor; sin perjuicio de lo dispuesto en el párrafo 68.1. La responsabilidad del establecimiento de salud conforme a esta norma es solidaria. (Ley N 29571 - Código de Protección y Defensa del Consumidor)

El primer numeral del artículo en mención establece la responsabilidad que recae sobre el establecimiento de salud con respecto a las actividades de los profesionales y en general del personal que ahí se "desempeñe”. En este caso, no se establece el tipo de relación que estos últimos tengan con el establecimiento. Es decir, únicamente está tomando al establecimiento médico como la cara del servicio frente al consumidor, sean dependientes del Establecimiento Médico o no, a diferencia de lo establecido en la Ley General de Salud que si menciona el tema de la "dependencia".

Ahora bien, en el siguiente numeral de este artículo, se establece que los profesionales podrían actuar de manera "independiente" en el establecimiento médico, únicamente utilizando la infraestructura y equipos de éste y es en este caso que la responsabilidad sería solidaria, es decir tanto el autor directo e indirecto responden.

Considero que la situación de independencia planteada en este artículo es un tanto gaseosa, ya que el criterio para la diferenciación vendría a ser netamente laboral, siendo que en el segundo caso estaríamos hablando de personal no vinculado laboralmente (es decir sin un contrato de trabajo) mientras que, en el primer caso, sería personal con un contrato de trabajo, interpretación que como se menciona anteriormente sería netamente laboral.

La diferencia entre una y otra figura en el marco de este capítulo, sería el tipo de responsabilidad en cada caso. En tal sentido, en el caso que no exista 
independencia, se entiende que en el numeral 1 del artículo, el establecimiento médico cuenta con una responsabilidad directa.

Adicionalmente, se establece un escenario más, el cual consiste en que no se utilice la imagen y reputación del establecimiento médico y que además la “independencia" haya sido previamente informada al consumidor. Es decir, en este caso, el establecimiento médico estaría fungiendo de un mero espacio para que el médico o grupo de médicos utilicen con la finalidad de llevar a cabo sus actividades profesionales pero sin que ello signifique el uso del mismo como una marca, figura que podría utilizarse a través de un contrato de arrendamiento, tal y como se menciona en el numeral 1.2.2 precedente, pero que en la realidad podría no estarse brindado efectivamente.

No obstante, se realizó la transferencia de funciones de Indecopi a Superintendencia Nacional de Salud (SUSALUD) conforme a lo dispuesto en el Decreto Legislativo 1158 del 14 de Agosto de 2015 con la finalidad que SUSALUD sea competente respecto a denuncias derivadas de vulneración a los derechos de las personas en materia de servicios de salud y seguros. Esta transferencia viene siendo gradual; por lo que, existen aún ciertos conflictos de competencia con Indecopi.

\section{- Pronunciamientos Relevantes:}

\section{SUSALUD (Resolución 017-2019-SUSALUD/TRI-TSE).:}

- Se presentó una queja contra la IPRESS Hospital II Suárez Angamos por haber proporcionado un tratamiento terapéutico distinto al prescrito por el médico especialista.

- Se determino a través del SAREFIS (Superintendencia Adjunta de Regulación y Fiscalización) responsabilidad administrativa a la IPRESS Hospital II Suárez Angamos por falta de idoneidad en el servicio prestado ya que se evidenció que el personal tecnólogo efectuó el cambio de la terapia de reflexología prescrita por el médico especialista, infringiendo el Código de Protección al Consumidor.

- En la mayoría de los casos, los servicios médicos están sujetos a una obligación de medios, debido a que no se asegura un resultado específico; no obstante, es necesario contar con la diligencia debida. 
- Es así que se concluye que un consumidor razonable esperar obtener de un médico un diagnóstico y estudios adecuados con la finalidad de recuperarse.

\section{- INDECOPI:}

○ $\quad$ Resolución 2268-2013/SPC-INDECOPI:

En este caso las conclusiones principales son:

1. El establecimiento de salud es responsable si sus médicos brindan un servicio que no sea idóneo cuando se encuentran en calidad de dependientes además de la responsabilidad personal del profesional.

2. En el caso de profesionales médicos independientes sin que dicha independencia haya sido informada; en ese caso, el médico y establecimiento de salud serán responsables solidariamente.

3. En el caso de profesionales dependientes del establecimiento médico, bajo las normas del Código de Protección al Consumidor no se podrá evaluar responsabilidad, pues esto deberá realizarse por la vía civil o penal.

\section{Resolución 0544-2014/SPC-INDECOPI}

En este caso las conclusiones principales son:

1. El profesional médico, en este caso, prestó el servicio médico de operaciones estéticas usando las instalaciones, herramientas e imagen del establecimiento médico; siendo que ello no implica el ejercicio independiente de la profesión, pues actuó como médico integrante al staff.

2. La cirugía estética es asumida como una obligación de resultado debido a que se espera un resultado específico destinado a obtener una mejora en la apariencia externa del paciente, siendo que si ello no es logrado se habrá infringido el deber de idoneidad. 


\subsection{Sentencias Judiciales Relevantes}

- Casación 220 - 2013 - LIMA: Flor de María Gonzales Villareal vs. Sociedad Francesa de Beneficencia y Jorge Chimoy Arteaga

- Se interpuso demanda de indemnización por daños y perjuicios debido a la negligencia médica imputada al Dr. Jorge Chimoy Arteaga, originando daños en su pierna derecha debido a un accidente automovilístico, siendo trasladada a la Clínica Maison de Sante.

- La demandante solicita el pago de S/15,000.00 por concepto de daño emergente y S/ 75,000.00 por concepto de daño moral.

- La demandante argumenta que el Dr. Chimoy realizó un procedimiento pinchando su pierna y cubriéndola con una férula, habiendo sido internada 9 días en la Clínica, días en los que no se le revisó la herida.

- Indicó que, el día que le dieron de alta, solicitó que se le revisara la pierna, estando infectada. Posteriormente, la Clínica Stella Maris confirmó la mala praxis efectuada.

- La demandante indica que no puede realizar sus actividades con normalidad debido a esta situación ni afrontar los gastos médicos.

\section{- Primera Instancia:}

Se declaró fundada la demanda, ordenándose pagar el monto de S/. 7,000 (Siete mil y 00/100 Soles) por daño moral, debido a:

- Existe es un daño leve e innecesario por el uso de calza de yeso y dación de alta antes de tiempo, existiendo relación de causalidad entre la conducta negligente leve y el daño transitorio producido a la paciente, conducta que se encuentra incursa en el artículo 1320 del Código Civil.

- Existe una relación contractual entre los codemandados de empleador-trabajador, por lo que la responsabilidad es solidaria frente a la demandante.

○ $\quad$ No pudo acreditarse debidamente lucro cesante y daño emergente. 


\section{- $\quad$ Segunda Instancia:}

Confirma la sentencia, declarándose fundada en parte la demanda y la revoca en cuanto ordena indemnizar en forma solidaria a la demandante con la suma de veinte mil nuevos soles por concepto de daño moral.

Dentro de sus fundamentos se encuentra:

- El tipo de responsabilidad utilizada es contractual, cuando debería ser extracontractual; no obstante, ello queda convalidado al no haberse apelado en este sentido.

- El médico actuó con culpa leve ya que se concluyó a través de las pericias que el médico demandado no uso el medio adecuado para tratar la lesión que tenía la paciente. No utilizó la diligencia media.

○ No es pertinente la aplicación del artículo $1762^{\circ}$ del Código Civil referida a prestación de servicios profesionales.

\section{Casación}

Dentro de los fundamentos esgrimidos por los demandados, alegaron: Infracción normativa de los artículos 1762 y 1981 del Código Civil e Infracción normativa de los artículos 139 inciso 5 de la Constitución Política, 2 de la Ley Orgánica del Poder Judicial y 122 inciso 3 del Código Procesal Civil,

La Sala Suprema, entre otros argumentos, indica: que :

○ No es aplicable el artículo $1762^{\circ}$ del Código Civil ya que el tratamiento de una herida que se produce en un accidente automovilístico no es un problema de especial dificultad.

○ Menciona que para saber cuándo un problema reviste especial dificultad, se evalúa la cantidad de técnicas existentes y lo consolidadas que se encuentren, mientras que si son más escasas o exista incertidumbre sobre ellas la responsabilidad se producirá cuando exista dolo o culpa inexcusable.

- La curación de la herida de la demandante le ocasionó un daño que debe ser reparado de manera solidaria por los codemandados en virtud a su relación de dependencia, conforme al artículo $1981^{\circ} \mathrm{del}$ Código Civil. 
- Se ha impugnado la aplicación indebida del artículo $1981^{\circ}$ del Código Civil, siendo que dicha norma regula los casos de responsabilidad civil extracontractual y éste sería un caso de responsabilidad civil contractual; no obstante, la Sala Suprema considera que no se ha producido el incumplimiento de un contrato, sino que no se actuó con la diligencia media debida, ocasionando un acto dañoso.

La casación en referencia precisa que el artículo $1762^{\circ}$ del Código Civil, es utilizado en casos de real complejidad, siendo que el presente caso no se enmarcaba dentro de este contexto. No obstante, es preciso indicar que esta norma es por demás subjetiva ya que el legislador ha dejado muy abierta la posibilidad de que, en otros casos, una situación pueda ser tomada como de "especial complejidad" a fin de tener que probar dolo o culpa inexcusable.

Es importante también poner de manifiesto el poco conocimiento demostrado por el juzgado en primera instancia, quien refiere que la responsabilidad es solidaria al tratarse de empleador - trabajador, siendo que nuestro Código Civil en los casos de responsabilidad contractual no establece solidaridad cuando el responsable se vale de terceros.

Ahora bien, para efectos de la materia, del presente trabajo de investigación, es interesante conocer la forma en que el juez menciona la necesaria "relación contractual" que debe existir entre el médico y el establecimiento de salud para poder realizar la aplicación del artículo 1981, ello en consonancia con la regulación indicada en la Ley General de Salud respecto a la situación de dependencia.

Estos conceptos dejan abierto el campo de acción de los establecimientos de salud a fin de que puedan utilizar maniobras para deslindar responsabilidad al utilizar a terceros que se encuentren en medio de la relación existente entre la entidad de salud y el médico que pueda generar que la relación contractual no sea directa. 
- Expediente No 1997-4784-0-0100-J-Cl-3: I.K.R. y M.T.C vs Clínica Ricardo Palma y Dr. A.F.G (Indemnización por Daños y Perjuicios).

○ La demandante fue programada para una operación de cesárea, habiendo dado a luz a una niña con estado de salud sano en la Clínica Ricardo Palma.

- El mismo día, doce horas después, la demandante presenta un cuadro de shock séptico, siendo trasladada a la Unidad de Cuidados Intensivos. El diagnóstico fue de tuberculosis peritonal.

○ Posteriormente, con fecha 01 de Octubre del mismo año, la demandante fue internada de emergencia en el Hospital Arzobispo Loayza por obstrucción intestinal a consecuencia de la operación efectuada en la Clínica Ricardo Palma.

○ En el Hospital Arzobispo Loayza, fue intervenida de una laparotomía exploratoria encontrándose múltiples bridas y adherencias intestinales, permaneciendo internada unos días más.

- En Diciembre, reingresa por emergencia al mismo hospital con un cuadro de suboclusión intestinal, siendo operada.

- La Clínica señaló que no le unía ninguna relación contractual con los demandantes ya que los médicos involucrados no son personal de la misma, ni les une ninguna relación laboral; por tal motivo, no les alcanza responsabilidad, siendo que el médico involucrado es titular de la razón social Servimedic Sanaldo.

- Indicaron además que, la administración no es responsable por actos que no son realizados por personal de su staff.

- Rechazan la afirmación de enriquecimiento ilícito debido a la deuda que mantenía el demandante en donde aceptó dos letras de cambio por la diferencia no pagada, habiendo la clínica iniciado las acciones de cobro que no prosperaron.

- La Administradora Clínica Ricardo Palma no ha realizado la operación que realizó el daño por dolo o culpa por cuanto no existe responsabilidad directa. 


\section{- Primera Instancia:}

Fue declarada infundada por los siguientes argumentos:

- La responsabilidad extracontractual es aquella que no se origina en contrato previo entre las partes, debiendo probarse la culpa.

- No se ha demostrado la existencia de algún indicio de responsabilidad objetiva o subjetiva del médico para determinar dolo o culpa.

- No se ha demostrado dolo o culpa de la Administradora Ricardo Palma.

\section{- Segunda Instancia:}

Se confirma la sentencia de primera instancia por los siguientes argumentos:

- La prestación de servicios profesionales médicos del presente caso, se encuentra establecida en el artículo $1762^{\circ}$ del Código Civil.

- Ya que existe una relación contractual entre las partes, es aplicable la normativa correspondiente a inejecución de obligaciones en el artículo $1330^{\circ}$ del Código Civil, en este caso la carga de probar el dolo o culpa inexcusable corresponde al perjudicado.

- Los medios probatorios presentados no acreditan dolo o culpa inexcusable de los demandados, correspondiente declarar infundada la demanda.

Considero que, en esta sentencia, la Sala no tuvo fundamentos adecuados en relación a los argumentos esgrimidos, pues manifiesta que no se ha probado si "Administradora Ricardo Palma" ha actuado con dolo o culpa inexcusable, siendo que va en contra de la naturaleza de la persona jurídica por ser un ente abstracto; es decir, el dolo o culpa inexcusable está relacionada a la conducta de la persona, no siendo posible atribuirlo a la persona jurídica.

Por otro lado, atribuir la carga de dolo o culpa inexcusable al paciente aplicando las normas de responsabilidad contractual por inejecución de obligaciones, resulta también algo desproporcionado puesto que el paciente no cuenta con los medios para probar un tema tan técnico como es una negligencia médica, en la que se necesitan argumentos especializados e informes de peritos correspondientes; es decir, el perjudicado entraría en una suerte de indefensión que lo privaría de contar con tutela judicial adecuada al encontrarse en la obligación de aportar evidencia sumamente difícil de obtener. 


\section{- $\quad$ Exp. N$^{0}$ 1518: A.D.C vs Clínica Maison de Santé, Clínica Internacional}

\section{(Indemnización)}

- Los hechos inician con el accidente sufrido por el menor hijo de la demandante, quien cae de la azotea de un inmueble en el que se encontraban celebrando una reunión social.

- Su menor hijo se encontraba en buen estado, caminando de manera consciente, con un hematoma, siendo dirigido a la Clinica Maison de Santé.

- Indica la demandante que el médico no aceptó su pedido para que le practiquen unas placas a fin de descartar lesiones internas; siendo que, el médico diagnosticó una lesión en la columna vertebral.

- La demandante manifiesta que contradecían el diagnóstico del médico respecto de una posible fractura ya que el menor se movía constantemente; no obstante, se quejaba de intensos dolores en el cuello.

- Como consecuencia de ello, se le suministró al menor una inyección intramuscular para calmar el dolor; siendo que cinco minutos después, le sobrevinieron fuertes convulsiones, continuando las mismas en el transcurso de las horas.

- Posteriormente, narra que las enfermeras se avisaban las unas a las otras para conseguir el oxígeno necesario; siendo que, a los minutos el médico les informó que su menor hijo había fallecido de insuficiencia cardiorrespiratoria.

- Indica que durante la noche su hijo no vio a ningún médico y que el neurocirujano había dado el diagnóstico vía telefónica, indicando que hubo imprudencia al aplicar el anestésico a su hijo, lo que ocasionó su muerte.

\section{- Segunda Instancia:}

Los principales argumentos fueron:

- Nos encontramos ante un escenario de daños sucesivos y no de concausalidad; por ello, cada demandado debe responder de manera independiente. 
- La Sala menciona que el principal responde porque a través del sistema de precios, se encuentra en la mejor posición para difundir más fácilmente el costo de los accidentes, declarando fundada en parte la demanda.

Podemos ver que, en esta sentencia, la Sala enfoca el argumento de la responsabilidad del Establecimiento Médico en uno de carácter objetivo. Es decir, dada la posición con la que cuenta el Establecimiento, quien conduce el negocio para lo cual se provee de distintos elementos (médico, personal técnico, insumos, etc.) es quien tiene el mejor escenario para poder responder por cualquier situación que se produzca.

\section{- Resolución $\mathbf{N}^{\circ} 130$ del Vigésimo Sétimo Juzgado Especializado en lo Civil} de Lima del 05.07.02:

- El demandante entró por emergencia a la Clínica, siendo derivado al consultorio del médico, habiéndose efectuado los cobros por dicha Clínica.

- La Clínica sostiene que no hay vínculo laboral entre la clínica y el médico pues este último ejerce de manera independiente la profesión, por lo que no se aplica la figura de la solidaridad.

\section{Primera Instancia}

- No existen medios probatorios suficientes aportados por la clínica para acreditar sus afirmaciones.

- La Clínica cuenta con responsabilidad contractual indirecta por hechos dolosos y culposos de terceros, debido a que el médico prestó sus servicios en la Clínica (art. $1325^{\circ}$ del Código Civil)

- La Clínica sume una obligación tácita de seguridad al prestar cuidados médicos, encontrándose obligado de manera solidaria con el médico (art. $1183^{\circ}$ del C.C.)

En esta sentencia, vemos que el Juzgado utiliza artículos referentes a la responsabilidad contractual atribuyendo la responsabilidad al establecimiento médico como consecuencia del incumplimiento de una obligación que depositó en un tercero; es decir, el médico. No obstante, nuevamente se habla de "solidaridad", siendo que esta consecuencia no es la que se indica para el escenario antes 
mencionado. Asimismo, se cita el artículo 1183 del Código Civil, el cual simplemente establece que la solidaridad debe estar pactada, lo cual no tiene relación con el artículo que se cita anteriormente y que no establece la solidaridad.

Como vemos de las sentencias antes citadas, nuestra jurisprudencia no es el mayor referente en cuanto a responsabilidad civil médica. Es necesario establecer criterios uniformes en primer lugar, respecto del tipo de responsabilidad al que nos encontramos sea contractual o extracontractual, aspecto que nuestra justicia no tiene claro al brindar sentencias contradictorias que menciona uno y otro artículo sin establecer distinciones. Por otro lado, es de verse que muchos de los establecimientos demandados han utilizado los argumentos de la "independencia" de los profesionales médicos que causaron el perjuicio de la víctima, mencionando que pertenecen a otras empresas (personas jurídicas creadas para estos fines según se estableció en párrafos precedentes) y que no están vinculados directamente a sus entidades.

No obstante, no se ha encontrado sentencia judicial que se pronuncie sobre esta figura jurídica, en muchos de los casos sí se declara fundada la demanda, pero por argumentos vacíos e incoherentes que dejan en interrogante muchas preguntas. Es así que, es necesario utilizar las herramientas legales correctas para atribuir responsabilidad, desenmascarando estas figuras utilizadas con la finalidad de que exista certeza en la víctima cuando necesite tutela de justicia.

\subsection{Derecho Comparado:}

\section{- Italia:}

El sistema de salud en Italia, establece obligaciones igualmente proporcionadas tanto para establecimiento públicos como privados. Asimismo, dada la cada vez mayor complejidad de la prestación de servicio de salud, se han ido cambiando los enfoques de la responsabilidad médica.

La línea tradicional nos decía que existía una responsabilidad solidaria del establecimiento médico frente al médico; sin embargo, la tendencia se centra en que el establecimiento médico tenga una responsabilidad directa, es decir, que exista una imputación de responsabilidad.

La normatividad se ha enfocado en los aspectos organizacionales y la calidad de las prestaciones sanitarias, haciendo que el legislador desplace la mirada de la actividad del médico y lo considere un sistema de la actividad sanitaria (más 
cerca a la actividad de empresa). El argumento frente al cual el establecimiento médico debe resarcir el daño producido es que éste se produce al interior del mismo, incumpliendo las denominadas "obligaciones accesorias".

La orientación tradicional anteriormente mencionada fue desarrollada en la década de los años 70, en este momento la responsabilidad se sustentaba en el hecho ilícito del médico, atribuyéndose la responsabilidad solidaria al médico (como responsabilidad extra contractual) y al establecimiento médico (como responsabilidad contractual).

Ya que la legislación italiana busca proteger al paciente, bajo este nuevo criterio, la carga de la prueba sería del establecimiento médico.

En este nuevo enfoque, la jurisprudencia no le presta relevancia a la prestación médica como una obligación de medios, sino en la carga probatoria proveniente del médico y establecimiento de salud.

En el modelo unitario de responsabilidad no importa si la imputación de la misma era a título contractual o extracontractual, a diferencia del modelo tradicional en el que se aplicaba distintos tipos de regímenes dependiendo si la responsabilidad era contractual o no. Este modelo unitario, tenía como base que el médico es un órgano del establecimiento médico y por ello se genera la responsabilidad de este último. El hecho ilícito del médico era el centro de la imputación, y la responsabilidad era solidaria entre médico y establecimiento de salud.

Posteriormente, se mantiene la responsabilidad unitaria, pero en base a las reglas de la responsabilidad contractual por incumplimiento de obligaciones, se añade el concepto de "contacto social". Por el lado del establecimiento médico, la prestación que ésta realiza fue volviéndose cada vez más compleja, siendo que la jurisprudencia nombró "el contrato de asistencia sanitaria" que incluye muchas prestaciones accesorias, adicionales a la prestación médica.

Dada la complejidad de la relación entre el paciente y el establecimiento de salud, el enfoque fue cambiando tanto a nivel jurisprudencial como legislativo, configurándose la responsabilidad directa del establecimiento de salud con el fundamento de incumplimiento de deberes y obligaciones. Es así que, la Corte de Casación en el año 2008 es independiente del ilícito atribuido al médico y 
tiene su fundamento en el incumplimiento de obligaciones. Aquí, se afirma la autonomía del establecimiento en cuanto la responsabilidad y se mencionan las obligaciones referidas a la asistencia sanitaria, así como organización y gestión. Asimismo, se estableció la naturaleza contractual de la relación del paciente con el médico, a través de la Sentencia de Casación del 27 de Enero de 1999 en virtud a la teoría del "contacto social", la misma que se refuerza con la Sentencia de Casación del 19 de Febrero de 2013.

Esta tesis sostiene que la responsabilidad del médico está basada en la negligente realización de la prestación sanitaria a la que está obligada el ente de salud. La modificación más importante del modelo tradicional al modelo unitario se produjo en la prueba liberatoria, siendo que ya no era la ausencia de culpa en el primer caso, sino la prueba del evento extraordinario y excepcional. Asimismo, existió una redistribución de la carga de la prueba, en el sentido que el médico y el establecimiento de salud debían probar dicho evento extraordinario y excepcional.

La tendencia de la jurisprudencia italiana se torna cada vez más rigurosa, siendo un modelo unitario de responsabilidad en donde existe un sólo hecho común. Así, adopta un criterio "semiobjetivo", manteniéndose la valoración de la culpa médica por violación de los deberes propios del ejercicio profesional sea como dependiente o como independiente. (Fernández Sessarego, C., Woolcott Oyague, O, 2018 p. 551 - 578)

\section{- Colombia}

La regulación colombiana se inclina por considerar la prestación médica como una de medios en su mayoría de casos y excepcionalmente de resultados. Así (...), la relación médico-paciente está reglada por un expreso acuerdo de voluntades, mediante el cual el médico queda comprometido, generalmente por una obligación de medios a empeñar todo su conocimiento, destreza y juicio clínico. Aunque ya la jurisprudencia nacional e internacional le ha asignado a ciertas áreas de la medicina la condición de obligación de resultados o fines. (Ruiz, 2004, p. 200) 
En este sentido se pronunció la Sentencia de Octubre 7 de 1999, exp. 12.655, Consejera Ponente Maria Elena Giraldo Gómez, indicando que principalmente que:

- El deudor, en el caso de éste tipo de profesiones, implica el cumplimiento de obligaciones de medio, indicando que los médicos sólo deben observar una conducta diligente, haciendo todo lo posible por obtener la cura del paciente.

- No obstante, la obligación médica implica una figura mucho más compleja, teniendo muchas más obligaciones por cumplir, teniendo deberes principales y secundarios.

○ Entre los deberes principales están: ejecución, diligencia en la ejecución, información y secreto médico.

- Entre los deberes secundarios: diagnóstico, elaboración de historia clínica, constancia escrita de datos relevantes, custodia del paciente, entre otros.

- De esta forma, debe averiguarse qué deber fue inobservado para determinar la responsabilidad del médico en cada caso concreto.

Esta sentencia nos muestra cómo el juez no sólo se remite a considerar la relación médica como una obligación de medios, sino que la establece como una relación compleja que establece obligaciones accesorias además de la obligación principal; es por ello que, en opinión del Juez debe evaluar específicamente las conductas incumplidas por parte del médico a fin de determinar el grado de responsabilidad y observancia o no de las medidas específicas.

Guzmán Mora, F. manifiesta que dentro del Capitulo IX, Título XXIV, Libro IV del Código Civil de Colombia, referente al arrendamiento de servicios inmateriales, dispone en el artículo 2069: «...Los artículos precedentes se aplican a los servicios que según el art. 2144 se sujetan a las reglas del mandato, en lo que no tuvieren de contrario a ellas...»

El artículo 2144 preceptúa: «...Los servicios de los profesionales y carreras que suponen largos estudios, o a que está unida la facultad de representar y obligar a otra persona respecto de terceros, se sujetan a las reglas del mandato...» Así las cosas, el servicio que prestan los médicos se regiría por la regulación relativa al arrendamiento de servicios inmateriales contenida en los artículos 2063 y ss del 
código civil colombiano y a las normas del mandato, artículo 2142 y ss del mismo código"

$(\ldots)$

La posición actual en Colombia, del Consejo de Estado (Sala de lo Contencioso Administrativo, Sección Tercera, Sentencia del 18 de Abril de 1994, expediente 7973, Magistrado ponente Dr. Julio Cesar Uribe Acosta) es la siguiente: «...el ad quem desea dejar en claro que la responsabilidad médica sigue siendo tratada en la Jurisprudencia de la Corporación como de MEDIOS, o sea de PRUDENCIA Y DILIGENCIA, lo que obliga al profesional de la medicina y a los centros de atención, a proporcionar al enfermo todos aquellos cuidados que conforme a los conocimientos científicos, y a la práctica del arte de curar, son conducentes para tratar de lograr el FIN deseado, siendo igualmente cierto que no se puede ni debe asegurar la obtención del mismo. Esta verdad jurídica impone que, de acuerdo con los principios generales que rigen la carga de la prueba, le incumbe al actor la demostración de los hechos en que funda su pretensión, y al demandado la prueba de los hechos que excusan su conducta. (p. 6-16) 


\section{CAPÍTULO III: EL LEVANTAMIENTO DEL VELO SOCIETARIO EN LA RESPONSABILIDAD CIVIL MÉDICA}

\subsection{Levantamiento del Velo Societario}

Si bien es cierto las personas jurídicas tienen la ventaja de brindar protección jurídica a los socios que la conforman, esto es limitar la responsabilidad, existen situaciones en donde dicho "manto protector" debe ser eliminado para cautelar otros derechos que pueden verse incluso más afectados por esta situación de intangibilidad, proporcionando así la tutela necesaria. Las personas jurídicas (lucrativas) se forman con el fin de realizar una actividad en común y perseguir un fin lucrativo con la misma; sin embargo, muchas veces esta figura es utilizada como "cascarón” para fines fraudulentos o abusivos.

\subsubsection{Concepto}

El levantamiento del velo como tal consiste en el desconocimiento de la protección que brinda la limitación de la responsabilidad societaria. Una vez permeado el velo societario, los socios-administradores entrarán a responder de manera solidaria e ilimitada por los daños que se hayan podido ocasionar a terceros. (Maldonado Narváez, 2016, p.88)

Así, aquello que se describe con el nomen "levantamiento del velo societario" no es más que la explicación del resultado práctico de una operación jurídica, esto es, la superación de la autonomía existencial y/o patrimonial de la personalidad jurídica. Si se quiere graficar en términos más simples, la formulación actual sólo nos explica aquello que se logra con la operación jurídica llamada levantamiento del velo societario. Inclusive la misma formulación también (e implícitamente) nos responde el por qué y para qué se desea lograr el resultado en cuestión, pero no nos dice nada del cómo se logra ello. Así, decir que se supera el efecto jurídico que diferencia a la persona jurídica de sus miembros es meramente describir el resultado último de la operación, pero no es la herramienta que lo logra, salvo desde luego que se crea que la mera declaración de la frase "levantamiento del velo societario" tiene casi el poder mágico que se le suele atribuir a la frase "abracadabra" y que una vez pronunciada todo lo que uno desea acaece en la realidad (jurídica). (Saavedra Velasco, 2016, p. 285) 


\subsubsection{Antecedentes}

Como indica Maldonado Narváez (2016), surge en los Estados Unidos como Disregard of legal entity" la cual de acuerdo con Hurtado (2000) es posible situarla por primera vez en el caso Bank of the United States v Deveaux, 1809, en la cual el juez que conoció de la misma sentenció que no obstante la parte involucrada en el proceso fuera una persona jurídica, en dicho caso debían responder como tal las personas naturales que la componían. (p.88)

Así, alegaban los mencionados socios que, siendo la sociedad una reunión de varias personas, ésta es invisible, inmortal, y su existencia solo descansa en su reconocimiento por la ley, por lo cual la persona jurídica no podía ser considerada "ciudadano". Ante tal situación el Juez Marshall se vio obligado a mirar más allá de la entidad, al carácter de las personas individuales que componían la sociedad, con el objeto de mantener la competencia del Tribunal Federal. A partir de esta sentencia, los casos de disregard of legal entity empezaron a ser cada vez más frecuentes. (Mispireta-Gálvez, 2018, p. 151, 152)

(...) la doctrina del levantamiento del velo surge echando sus raíces en postulados genéricos existentes en los ordenamientos jurídicos de origen anglosajón; pero fundamentalmente ha sido la aplicación de la equidad (equity) la que ha permitido a los magistrados alcanzar la justicia a través del desconocimiento de la personalidad jurídica y la extensión de responsabilidad a los miembros que la componen. (Mispireta-Gálvez, 2018, p. 153)

Posteriormente a esta sentencia, en otro caso muy famoso en Inglaterra, Salomon v Salomon y Co Ltd, 1897, la Cámara de los Lores revocó un fallo que en primera y segunda instancia había sido dado a favor del levantamiento del velo, alegando que la persona jurídica era hermética y que como tal no había manera de permearla. Si bien nos apartamos de la postura asumida por la Cámara de los Lores en el citado caso, el mismo sirve para mostrar como el levantamiento del velo es una figura que opera únicamente de manera excepcional (Maldonado Narváez, 2016, p.88)

Debido a lo antes expuesto, la doctrina del levantamiento del velo (disregard of leal entity) surge en la jurisprudencia anglosajona por la necesidad de concretizar una protección efectiva en favor de los acreedores o terceros en general, que puedan verse perjudicados por la comisión de actos contrarios al ordenamiento jurídico, realizados a través de instituciones colectivas que son usadas como meros instrumentos o "pantallas" por sus miembros, los 
cuales son en realidad los que se benefician ilegítimamente con dichos actos. (MispiretaGálvez, 2018, p. 155)

En Francia, existió un acelerado crecimiento tecnológico y empresarial que se originó con las revoluciones industriales, el cual fomentó la masiva creación de sociedades con responsabilidad limitada. Por ello, aparecieron procedimientos que hicieron posible una regresión para atribuir responsabilidad patrimonial a los socios o a quienes actuaron detrás de una maquinaria social, en beneficio propio y en detrimento de tercero, utilizando para ello la figura del ejercicio abusivo del derecho.

Como antecedente más cercano tenemos el primer pronunciamiento jurisprudencial que se dio en España sobre la aplicación del levantamiento del velo societario, es la sentencia emitida por la Sala Primera el 28 de Mayo de 1984. Este constituye el primer caso en donde se utiliza en forma expresa el "levantamiento del velo de la Persona Jurídica” (...) (Saavedra Gil, 2018, p. 191 y 192)

\subsubsection{Abuso de Derecho y Fraude a la Ley}

- Abuso de Derecho

El concepto de abuso de derecho es bastante variable en la doctrina y no hay una posición uniforme al respecto. Según Saavedra Gil, es una conducta que, sustentándose en un derecho subjetivo, se convierte en antisocial al transgredir en su ejercicio, o a través de su omisión, un genérico deber jurídico que cristaliza el valor solidaridad. Ello origina un sui generis que no es materia de la responsabilidad civil. Lo antisocial es lo "irregular", "lo anormal", es decir, contrario a la solidaridad $\mathrm{y}$, por ende, a la moral social. (Como se citó en Mispireta Galvez, 2018, p. 82)

Es decir, el abuso de derecho implica el ejercicio de un derecho que se encuentra contemplado en la norma; sin embargo, transgrede los fines del derecho; es así que este concepto se encuentra regulado en nuestra Constitución Política, en su artículo $103^{\circ}$ indicando que: "La Constitución no ampara el abuso del derecho." Asimismo, (...) el derecho subjetivo es la facultad que se atribuye a un sujeto de derecho y la titularidad de ese derecho es reconocido por el ordenamiento jurídico positivo. En segundo lugar, está la situación jurídica subjetiva que es la consideración del ser humano no solo como individuo sino también como ser 
social. Entonces el abuso de derecho es un ilícito sui generis, que se origina en el ejercicio extralimitado de un derecho subjetivo, ante el desconocimiento del deber que va implícito en todo derecho. (como se citó en Saavedra Gil, 2018, p.112)

A continuación, los siguientes elementos de juicio acerca del abuso del derecho son los siguientes:

- $\quad$ El punto de partida es la situación jurídica subjetiva.

- $\quad$ Se transgrede un deber jurídico genérico (buena fe o buenas costumbres inspiradas en el valor solidaridad).

- $\quad$ Es un acto ilícito sui generis

- Se agravian intereses patrimoniales ajenos y no tutelados por una norma jurídica específica.

- $\quad$ Ejercicio de un derecho subjetivo de modo irregular.

- $\quad$ No es necesario que se verifique el daño.

- Su tratamiento no debe corresponder a la responsabilidad civil sino a la teoría general del derecho. (como se citó en Saavedra Gil, 2018, p. 112 y

- $\quad$ Fraude a la Ley

El fraude a la ley se presenta como en apariencia como un acto legítimamente realizado y bajo el amparo de normas legales expresas. Para que exista fraude a la ley deben existir dos normas jurídicas, una que es la llamada "ley de cobertura" y la otra que es la "ley defraudada". La ley de cobertura es un dispositivo general que permite encubrir el acto malicioso y darle un tono aparente de legalidad. La ley defraudada, en cambio, no es un precepto específico para un caso determinado, lo que se atenta de esta norma es la finalidad por la cual fue creada; es decir, se ataca la razón - ratio legis - que llevó al legislador a emitir este dispositivo. (Mispireta Galvez, 2018, p.99)

El acto in frauden legis tiene una apariencia de legalidad que le confiere la norma de cobertura, pero en realidad carece de legalidad por haber sido realizado con el fin de eludir una norma imperativa que lo prohíbe, por lo que carece de idoneidad para producir un resultado similar al prohibido y por consiguiente es nulo. (como se citó en Saavedra Gil, 2018, p.123) 
De esta forma, el fraude a la ley contempla una forma de "burlar" los fines de la norma a través de otra norma de cobertura que envuelve al acto en una suerte de legalidad que no existe.

Así, Mispireta Galvez señala que no se puede hacer una extensión demasiado general al momento de aplicar la figura jurídica del fraude a la ley, pues hay que recordar que, como contraparte de la misma, debe respetarse el principio de seguridad jurídica; más, teniendo en cuenta que el acto o los actos que podrían considerarse defraudatorios se hacen dentro del marco legal que le brinda la norma de cobertura. Sin embargo, sí creemos que, los efectos del fraude a la ley pueden extenderse en los casos en que se viole la finalidad que podría tener un sistema normativo determinado; esto es, cuando se atenta contra los objetivos que se han tenido para crear un ordenamiento legal referido a determinada situación de hecho bastante bien delimitada. (Mispireta Galvez, 2018, p.100)

Respecto al fraude a la ley, algunos autores consideran que es necesaria la existencia de un daño o bien jurídico perjudicado, otros en cambio consideran que ello no es necesario en la medida que se está atentando contra los objetivos perseguidos por la norma y el ordenamiento jurídico.

Según Mispireta Galvez, algunos abusos y fraudes realizados a través de la persona jurídica son:

- Infracapitalización de la Persona Jurídica: Esta situación se da cuando la persona jurídica no cuenta con los medios económicos suficientes para cumplir con su objeto y obligaciones. Así, puede ser al constituirse la sociedad (infracapitalización) o en el transcurso de ésta (infrapatrimonialización).

Asimismo, se habla de dos tipos de infracapitalización:

- Material: En este caso, la Sociedad no puede cumplir con sus obligaciones debido a que las aportaciones al constituirse fueron menores a su objeto social.

○ Nominal: Cuando existen créditos otorgados a la sociedad.

- Grupos Económicos:

Se trata de aquellos casos de "grupos de empresas" o "grupos de control", así las características de dichos grupos son: 
- Dirección centralizada de un conjunto de empresas

- Maximización de la rentabilidad a largo plazo del conjunto de empresas y no de cada una individualmente.

- Por su tamaño, ejerce algún tipo de presión en las políticas públicas.

- Redu cción de riesgo de sus inversiones a través de la diversificación de sus actividades.

○ Información pública para todas las empresas

- Innovación y modernización en todas las facetas del proceso de producción.

- Movilizar con rapidez algunos recursos como el capital financiero.

Saavedra Gil (2018) menciona algunas reglas básicas que se debe tener en cuenta para el uso del levantamiento del velo societario en el caso de grupos de empresas:

“cuando la actuación de la Sociedad encubra la consecución de fines extrasocietarios a través del fraude a la ley o utilización indebida de la forma de la sociedad, cuando se burle el orden público o la buena fe perjudicando o frustrando el derecho de terceros. Además, que se someta mediante la dirección unificada el interés del controlante o de la controlada (prime el interés particular de cada sociedad antes que el interés grupal). (p. 162).

No obstante, según se puede observar en la literatura realizada, los supuestos no se limitan pudiendo haber mayores casos de grupos de empresas.

- Confusión Patrimonial y Confusión de Esferas:

Se puede describir a la confusión de Patrimonios cuando el patrimonio de la Sociedad y de quienes la conforman no puede diferenciarse claramente o es difícil distinguirlas a ambas como sujetos de derecho diferentes (es decir, si actúa uno u otro). Según indica Saavedra Gil (2018) “este tipo de casos se presenta en las Sociedades que comparten todos o la mayoría de sus miembros. (p. 177)

Asimismo, diversos autores comparten la teoría que la mayoría de casos en que esto ocurre tiene que ver con personas jurídicas formadas por un 
sólo integrante, como en el caso de la Empresa Individual de Responsabilidad Limitada.

\subsection{Aplicación de la teoría del Levantamiento del Velo Societario en el derecho laboral:}

La Teoría del Levantamiento del Velo Societario en materia laboral ha sido considerada por la judicatura en algunas oportunidades a fin de cautelar los derechos laborales de trabajadores que reclamaban el pago de sus beneficios sociales.

Es así que, muchos autores manifiestan que dicha aplicación debe ser realmente cautelosa, ya que se trata de desbaratar la estructura jurídica y protección que supone encontrarse bajo el manto de la responsabilidad limitada que se tiene a través de la persona jurídica. No obstante, la protección de los derechos que se encuentran en juego así lo justifican.

En consecuencia, en la actualidad, la tendencia de las empresas es la de operar a través de otras, hecho que va tener implicaciones para sus trabajadores internos como externos, dependientes e independientes, al menos en apariencia. Así se presentan fenómenos de encubrimiento y de situaciones objetivamente ambiguas que son susceptibles de crear una situación de desprotección de los trabajadores, derivada de la inaplicación parcial o total de la legislación laboral. Estos casos de apariencia, disfraz o encubrimiento que constituyen fraude a la ley, por lo general, se generan en "relaciones triangulares" y "fenómenos de encubrimiento", en los cuales se contrata a empleados dentro de los parámetros establecidos en la legislación laboral vigente. Pero el objeto real es crear una relación aparente a fin de poder obtener algún tipo de beneficio. En estos supuestos no existe duda de la relación laboral; sin embargo, es difícil determinar quién es su verdadero empleador y cuáles son los derechos o deberes que éstos tienen respecto del empleado. Lo singular de los supuestos de trabajo disfrazado, donde el vínculo obligacional que lo origina no es claro, es que se crea una apariencia distinta de la relación de trabajo, respecto de la que le dio origen para de este modo impedir una adecuada protección de nuestro ordenamiento al empleado y evadir de este modo sus obligaciones. En la práctica esta figura puede ser utilizada para ocultar la identidad de la empresa empleadora, por ejemplo, cuando se menciona la calidad de este resultando ser solamente un mero intermediario que libera al empleador de sus obligaciones laborales. (Guerra Cerrón, 2007, p.281,282). 
Es claro que los derechos laborales y sobre todo los beneficios sociales son amparados de manera primordial por el estado, el empleador tiene la obligación de respetar dichos derechos por ser inherentes a los trabajadores de igual manera resulta necesario conocer que existen fenómenos económicos y sociales que afectan las relaciones individuales de trabajo así se tiene el incumplimiento del pago de los beneficios sociales. (Farfán Pacheco, 2018, p.28,29).

\section{- Derecho Comparado:}

En derecho comparado tenemos el caso de Chile, en la que la teoría no se encuentra regulada normativamente, pero que sin embargo la Corte Suprema de este país indico lo siguiente en una sentencia "esta Corte considera útil establecer que constituye un derecho del hombre organizarse para producir. La ley tiene que reconocerle ese derecho. Tal facultad del ser humano ha ido variando, en cuanto a su forma de ejercicio, con el transcurso del tiempo y ha ido adoptando evolucionados y diferentes modelos. Uno de ellos es el denominado "holding" o conjunto de empresas relacionadas. Atento a tales cambios, en la especie, ha de hacerse primar el principio de la realidad, eso es, la verdad o la autenticidad en las relaciones laborales, aquello que son y no lo que las partes han querido que sean”. (Rol No 1 933-2001, 2001) (como citó en Farfán Pacheco, 2018, p.48).

En el país de Argentina de igual manera la teoría del levantamiento del velo societario no se encuentra legislada, siendo así que establece los parámetros para su aplicación de manera jurisprudencial, haciendo referencia al abuso de derecho como una condición para la aplicación de la misma, si bien existe el artículo 54 del Texto ordenado de la ley de sociedades comerciales de Argentina, en la que sanciona el dolo o culpa del socio o del controlante, se sostiene que la base de esta teoría radica en la equidad, de igual manera hace referencia que no se necesita de la habitualidad en el uso fraudulento de la persona jurídica, sino indica que sólo se necesita de un acto para desestimar la personalidad jurídica (como citó en Farfán Pacheco, 2018, p.49). 
- Pronunciamientos de la Justicia Nacional en torno a lo indicado:

- Casación Laboral No 328-2012 LIMA:

- Desconocer la personalidad jurídica en una sociedad puede ser beneficioso en algunos casos de incumplimiento de obligaciones laborales a fin de imputar la responsabilidad de manera individual y salvaguardar la empresa.

- No deben existir normas que sirvan como escudos legales para no cumplir con una obligación regulada en perjuicio de los trabajadores, pues los empresarios deben cumplir con la ley.

- Existen casos en que se utiliza la libertad de asociarse para desconocer obligaciones laborales, se busca que todos los grupos empresariales actúen con lealtad y de buena fe.

EXP. No 7172-2006 BE(A) Resolución de fecha 08 de marzo de 2007, la

\section{Segunda Sala Laboral de Lima:}

- La demandada constituyó una EIRL con un capital de S/1,000 valorizado en bienes entre sillas y mesas.

- La Sala advierte que la creación de esta empresa constituye un abuso de derecho de la titular a fin de poder realizar actividades ilícitas que no comprometan su patrimonio.

- La Sala considera que esta empresa unipersonal fue constituida con un capital ínfimo a fin de no asumir obligaciones con terceros, en este caso el trabajador, quien no recibió el pago de sus beneficios sociales.

- Siendo así, al no contar la empresa con recursos que le permitan el cumplimiento de sus obligaciones, corresponde la aplicación de la fgura del levantamiento del velo societario, siendo que se prescinde de la figura societaria.

- EXP. No 5005-2011 BE(S), la Sala Transitoria Laboral de Lima, mediante resolución de fecha 30 de setiembre de 2011:

- Se determina que la demandante ha formado una EIRL, mediante abuso de derecho ya que no arriesga su patrimonio al no asumir con su obligación contraída con el trabajador. 
○ Se concluye que el trabajador ha prestado servicios para la demandada; por lo que, corresponde la aplicación de la figura de Levantamiento del Velo Societario y Primacía de la Realidad.

- La actitud de la demandada en la constitución de una empresa para eludir la responsabilidad, denota una actitud de fraude en perjuicio del trabajador.

De las sentencias anteriormente expuestas, vemos que los jueces reconocen que los empresarios no deben valerse del manto protector otorgado por la personalidad jurídica a fin de desproteger los derechos de los trabajadores, ello en muchos casos, en el marco de trabajadores que rotan de empresa en empresa en grupos empresariales, modalidad muy comúnmente utilizada en nuestra realidad nacional.

Vemos también en otro pronunciamiento, que el Juez laboral analiza el funcionamiento de la persona jurídica en el sentido que al tener la misma un patrimonio ínfimo que no le permite el cumplimiento de obligaciones para con sus trabajadores se presume que la misma fue creada con la finalidad de eludir el pago de beneficios sociales. Es decir, el Juez laboral ha ingresado en la esfera más profunda de la persona jurídica para determinar que no le era aplicable la responsabilidad limitada que ésta otorga.

Asimismo, no sólo aplica la doctrina del levantamiento del velo societario, sino que también el principio de primacía de realidad para priorizar las labores que realice el trabajador en la empresa, sea cual fuere la razón social a la que pertenezca aparentemente. 


\section{CAPITULO IV: PROPUESTA DE APLICACIÓN DE LA TEORÍA DEL LEVANTAMIENTO DEL VELO SOCIETARIO EN LOS CASOS DE RESPONSABILIDAD CIVIL MÉDICA}

La salud privada en el Perú, como bien se ha expuesto en líneas precedentes pertenece a ciertos grupos económicos poderosos que concentran la mayoría de clínicas o centros médicos existentes en el país.

Es así que las demandas por causa de responsabilidad civil médica no son pocas; sin embargo, son variadas y los resultados no contienen criterios jurisprudenciales uniformes.

En definitiva, la atención del paciente no está solo en manos del médico, individualmente considerado, que asumió la ejecución de la prestación de salud, sino de la completa estructura de salud. Consiguientemente, las soluciones a los problemas de daños médicos deben ser individuadas dentro de una "responsabilidad sanitaria", más que de una responsabilidad individual del médico. (Woolcott Oyague, 2006, p.393)

De esta forma, se hace presente la necesidad de desentrañar los sistemas que utilizan las instituciones médicas para brindar los servicios a sus pacientes, evidenciando que muchas de ellas utilizan personal médico calificado de "staff" (o no necesariamente) mediante la creación de estas empresas que se vinculan con el establecimiento a través de distintas figuras contractuales, buscando como único propósito el de limitar responsabilidad.

Cieza Mora (2013) considera que, en función a la teoría de la apariencia, el Establecimiento Médico debe responder en todos estos casos, así indica que el argumento de la Clínica Ricardo Palma nos permite identificar un sustento común ahora por muchas clínicas que obligan a los médicos a constituir personas jurídicas independientes que son empresas formadas por una o dos personas, con la finalidad de evitar la responsabilidad civil y el pago de las reparaciones a las víctimas del daño médico. Considero que el argumento civil para neutralizar este argumento es el del principio de apariencia que va a determinar que el paciente acude a un determinado médico o a un médico que aún no conoce, hasta que la atiende, por la seguridad que le garantiza la estructura sanitaria y todo lo que esta implica. El paciente acude a la clínica por el prestigio, la solvencia, la capacidad instalada médica, las respuestas del establecimiento ante eventuales contingencias o eventos adversos. La 
atención del médico es algo complementario o concurrente pero no único para determinar al paciente a acudir a una clínica. (p.61)

Vemos que este autor nos habla sobre la teoría de la apariencia como medio para neutralizar estas prácticas.

Respecto a la apariencia se dice que la situación manifestante puede estar constituida por un hecho cualquiera; en cambio, la situación manifestada - que aparece, pero que no es real- está constituida, necesariamente, por una situación jurídica, que es normalmente la titularidad de un derecho subjetivo. Ello no significa que la falsa remisión realizada por la situación generadora de apariencia no pueda referirse a otra situación de hecho: pero ha de tratarse de un hecho jurídico tomado en cuenta, exclusivamente, por los efectos que produce, de manera tal que siempre se referirá a una situación jurídica. En lo anterior radica, por lo demás, una de las razones fundamentales de la relevancia para el derecho del fenómeno de la apariencia, porque la realidad jurídica escapa, por lo general, de la posibilidad de una determinación segura, y requiere, como quiera que sea, de amplias y complejas investigaciones. (Falzea, 2006, p.193).

Sin embargo, considero que la teoría de la apariencia no es suficiente a efectos de poner de manifiesto el sistema que arma el establecimiento médico. Es aquí donde se propone la aplicación de la figura de levantamiento del velo societario.

Podemos decir entonces que estas empresas se encuentran en un contexto de infra capitalización del tipo material; es decir, son creadas con capitales ínfimos que no les permiten el cumplimiento de sus obligaciones.

Hemos visto en el primer capítulo que las características de estas empresas, sugieren una intención defraudatoria en la medida que son constituidas con fines específicos (que muchas veces está plasmado en su objeto social), capital social minúsculo que nunca llega a ser aumentado, actividad limitada de la persona jurídica, al no registrarse mayores actividades societarias salvo las que son necesarias por mandato legal, única relación comercial con el establecimiento médico correspondiente, pudiendo llegar a incluir parte del nombre del establecimiento en su denominación social. Es así que, muchos de estos establecimientos tienen incluso publicitado en sus locales el deslinde de vinculación que tienen con estas empresas con el argumento de que trabajan independientemente y no son responsables por los actos de éstas.

El levantamiento del velo societario en estas empresas creadas vendría a ser justificado entonces para cautelar los derechos de los perjudicados en los casos de responsabilidad médica. La consecuencia sería que, quienes se encuentren detrás de la 
misma, (que pueden ser varios médicos o el mismo Centro Médico) puedan hacerse cargo de reparar a las víctimas en caso de ser encontrados culpables.

Es así que, la responsabilidad dependiendo de cómo ésta sea determinada, podría recaer tanto en el establecimiento médico, el médico tratante, así como todos los socios detrás de la persona jurídica creada para contratar y a quien le atribuyen la responsabilidad. En muchos casos, este socio es el propio establecimiento, en otros varios médicos. Todos estos actores serían parte de la bolsa respecto de la cual el perjudicado debería cobrar los daños y perjuicios solicitados. 


\section{CONCLUSIONES}

- Actualmente, la mayoría de establecimientos médicos privados en el país pertenecen a los grandes grupos económicos dominantes, teniendo éstos el control de los servicios que se prestan.

- Una modalidad frecuentemente utilizada por los establecimientos médicos privados para contar con personal médico es contratar con empresas creadas por estos médicos y que en realidad son manejadas por el mismo establecimiento, con la finalidad de deslindar responsabilidad en sus actos.

- Del análisis que se realiza de las "empresas médicas" creadas, se denotan características especiales que evidencian un fin de apariencia (capital, actividades, objeto).

- No existe consenso respecto al carácter contractual o extracontractual de la responsabilidad civil médica. Sin embargo, la postura mayoritaria de la doctrina, es que la misma es una responsabilidad contractual, existiendo situaciones específicas en las que la misma puede ser extracontractual.

- El Derecho de consumidor también se ocupa de la responsabilidad médica administrativa en su normativa, siendo así, establece los supuestos en los que los profesionales médicos o técnicos se desempeñan en sus instalaciones, diferenciando de aquellos en los cuales hay independencia en sus funciones pero que utilizan la infraestructura del centro médico.

- De la revisión de la jurisprudencia revisada, se ha encontrado incongruencias en la aplicación de la normativa vinculada a responsabilidad civil, ya que no existe un criterio uniforme respecto al tipo de responsabilidad aplicable.

- La figura del levantamiento del velo societario no se encuentra regulada en nuestro país; no obstante, ha sido aplicada en varias oportunidades en materia laboral con la finalidad de hacer valer el derecho del trabajador en el pago de sus beneficios sociales. 
- Existen pronunciamientos por parte del Poder Judicial en materia laboral, en el que el Juez Laboral realiza un análisis sobre la persona jurídica a cuya planilla responde el trabajador, con la finalidad de evidenciar una intención de fraude a la ley y así levantar el velo societario y se inaplique la responsabilidad limitada.

- Considero que es posible utilizar de ejemplo la práctica realizada en materia laboral con la finalidad de salvaguardar los derechos del trabajador para trasladarlo a los casos de responsabilidad civil médica en las que el establecimiento médico pretende desconocer o limitar su responsabilidad, indicando que el médico que realizó el acto dañoso pertenece a otra empresa y que no es parte de su "staff".

- La figura del levantamiento del velo societario en los casos de responsabilidad civil médica para el caso señalado, permitiría que la persona perjudicada cuente con mayores recursos para obtener la reparación civil que le corresponde. 


\section{REFERENCIAS}

Fernández Sessarego, C., Woolcott Oyague, O., (2018). Derecho médico: De las nociones fundamentales y la responsabilidad médica (Primerán. ed.) Lima: Instituto Pacífico

Cieza Mora, Jairo (2013) Nuestra jurisprudencia y la responsabilidad civil médica. Diálogo con la Jurisprudencia $\mathrm{N}^{\circ} 177$ p. $51-73$

García Huayama, Juan Carlos (2015) La Responsabilidad Civil en el Perú. Recuperado de https://dialnet.unirioja.es/descarga/articulo/5456406.pdf

Cieza Mora, Jairo (2013) La responsabilidad civil médica. Criterios de imputación (factores de atribución) y el dilema sobre su contractualización”. Actualidad Jurídica, Tomo 231, Gaceta Jurídica, Lima, pp. 72 - 89.

Bueres, A. J. (1981). Responsabilidad civil de las clínicas y establecimientos médicos. Buenos Aires: Ábaco.

Bergoglio de Brouwer de Koning, María Teresa. (1989). La responsabilidad civil: Profesionales de la salud. Establecimientos asistenciales. Córdoba: Advocatus.

Mozos, José Luis de los, \& Soto Coaguila, C. A. (2006). Responsabilidad civil: Derecho de daños: Responsabilidad de los profesionales, responsabilidad de las personas jurídicas y del estado. Lima: Jurídica.

Galán, Cortés, Julio Cesar. (2011). Responsabilidad civil médica. Cizur Menor. Edit. Thomson-Civitas. Madrid

Agón López, J. G. (2017). Consentimiento informado y responsabilidad médica. Madrid: Wolters Kluwer España.

Seijas Rengifo, Teresa de Jesús. (2001). Derecho médico I: Aspectos legales del ejercicio médico y su responsabilidad profesional. Lima. Editorial Horizonte.

Fernández, S. C., Rabinovich-Berkman, R. D., \& Wagner, G. P. (2011). La responsabilidad civil del médico y el consentimiento informado. Lima. Editorial Motivensa.

Varsi-Rospigliosi, E. (2006). Derecho médico peruano: Doctrina, legislación \& jurisprudencia (2a. act. amp. y rev. ed.). Lima. Grijley.

Manuell Lee, G. R. (2005). El acto médico y su regulación jurídica. Revista CONAMED, No. 1. Pags. 5-7.

Vera Carrasco, Oscar (2013) Aspectos Éticos y Legales en el Acto Médico. Revista Médica La Paz.http://www.scielo.org.bo/scielo.php?script=sci_arttext\&pid=S172689582013000200010 
Guzmán, F., Franco E., Morales de Barrios, M., Mendoza, J. (1994) El Acto Médico. Implicaciones éticas y legales. Acta Médica Colombiana Vol. 19 №3. Pags. 139149. http://www.actamedicacolombiana.com/anexo/articulos/03-1994-05 El_acto_medico.pdf

Seijas Rengifo, Teresa de Jesús. (2001). Derecho médico I: Aspectos legales del ejercicio médico y su responsabilidad profesional. Lima: Horizonte.

Yungano, A. R. (1986). Responsabilidad profesional de los médicos: Cuestiones civiles, penales, médico-legales, deontológicas (2a ed.). Buenos Aires: Universidad.

Lasso EC, Clara Isabel Posada Abadía (2007) Análisis de la responsabilidad médica desde la óptica de la responsabilidad civil y su evolución jurisprudencial. Unpublished.

Guzmán Mora, F. (2001). Criterios para definir la responsabilidad civil del acto médico en colombia. Revista CONAMED, Nº. 21, Pags. 6-16

León Hilario, L. L. (2017). La responsabilidad civil: Líneas fundamentales y nuevas perspectivas (Tercerán. ed.). Lima: Instituto Pacífico S.A.C.

Lorenzetti, R. L. (2005). Responsabilidad civil de los médicos. Lima: Grijley.

Giraldo, L. F. (2009). La relación de causalidad en los procesos de responsabilidad civil médica profesional. Revista Médico Legal, p. 28

Farfán Pacheco, S.I (2018) Tratamiento y aplicación de la Teoría del Levantamiento del Velo Societario en grupos empresariales para garantizar el pago de beneficios sociales en el derecho peruano. (Trabajo de Investigación para optar el grado de magíster en derecho de la empresa) Pontificia Universidad Católica del Perú. http://tesis.pucp.edu.pe/repositorio/handle/20.500.12404/13421

Maldonado Narvaéz, Marlón Ivan (2016). Levantamiento del velo societario en Colombia. un análisis del artículo 43 de la ley 1258 de 2008. Revista e-Mercatoria, https://revistas.uexternado.edu.co/index.php/emerca/article/view/5064

Saavedra Velaszco, Renzo E. (2016). Breve itinerario acerca de las teorías civiles de la personalidad jurídica. Su impacto en el common law y en el levantamiento del velo societario. Derecho \& $\quad$ Sociedad 36. https://repositorioacademico.upc.edu.pe/bitstream/handle/10757/604684/Teor\%C3 \%ADasCiviles.pdf?sequence $=1 \&$ isAllowed $=y$

Toledo Toribio Omar y Arauco Vivas Tania Tula (2017) "El levantamiento del Velo Societario en el Proceso Laboral Peruano", Soluciones Laborales $N^{\circ} 110$

Mispireta-Gálvez, C., \& Instituto Pacífico (Lima). (2018). Abusos y fraudes realizados a través de la persona jurídica: Problemas y alternativas de solución en el derecho peruano (Primerán. ed.). Lima: Instituto Pacífico.

Saavedra Gil, R. (2009). El levantamiento del velo societario: Doctrina, legislación y jurisprudencia. Lima: FECAT. 
Woolcott-Oyague, O. (2006). Los daños médicos en el sistema de salud peruano: ¿Un problema solo de la responsabilidad civil? Perú

Ruiz, Wilson (2004) La Responsabilidad Médica en Colombia. Criterio Jurídico. Santiago de Cali 